OPEN ACCESS

Edited by:

Anne Puel,

Institut National de la Santé et de la

Recherche Médicale (INSERM),

France

Reviewed by:

Mike Recher,

Universität Basel, Switzerland

John Bernard Ziegler,

Sydney Children's Hospital, Australia

*Correspondence:

Stephen Jolles

jollessr@cardiff.ac.uk

Specialty section

This article was submitted to Primary Immunodeficiencies,

a section of the journal

Frontiers in Immunology

Received: 11 July 2018 Accepted: 08 January 2019 Published: 08 February 2019

Citation:

Patel SY, Carbone J and Jolles S (2019) The Expanding Field of

Secondary Antibody Deficiency: Causes, Diagnosis, and Management.

Front. Immunol. 10:33. doi: 10.3389/fimmu.2019.00033

\section{The Expanding Field of Secondary Antibody Deficiency: Causes, Diagnosis, and Management}

\author{
Smita Y. Patel ${ }^{1}$, Javier Carbone ${ }^{2}$ and Stephen Jolles ${ }^{3 *}$ \\ ${ }^{1}$ Clinical Immunology Department, Oxford University Hospitals NHS Foundation Trust, Oxford, United Kingdom, ${ }^{2}$ Clinical \\ Immunology Department, Hospital General Universitario Gregorio Marañon, Madrid, Spain, ${ }^{3}$ Immunodeficiency Centre for \\ Wales, University Hospital of Wales, Cardiff, United Kingdom
}

Antibody deficiency or hypogammaglobulinemia can have primary or secondary etiologies. Primary antibody deficiency (PAD) is the result of intrinsic genetic defects, whereas secondary antibody deficiency may arise as a consequence of underlying conditions or medication use. On a global level, malnutrition, HIV, and malaria are major causes of secondary immunodeficiency. In this review we consider secondary antibody deficiency, for which common causes include hematological malignancies, such as chronic lymphocytic leukemia or multiple myeloma, and their treatment, protein-losing states, and side effects of a number of immunosuppressive agents and procedures involved in solid organ transplantation. Secondary antibody deficiency is not only much more common than $\mathrm{PAD}$, but is also being increasingly recognized with the wider and more prolonged use of a growing list of agents targeting B cells. SAD may thus present to a broad range of specialties and is associated with an increased risk of infection. Early diagnosis and intervention is key to avoiding morbidity and mortality. Optimizing treatment requires careful clinical and laboratory assessment and may involve close monitoring of risk parameters, vaccination, antibiotic strategies, and in some patients, immunoglobulin replacement therapy $(\operatorname{lgRT})$. This review discusses the rapidly evolving list of underlying causes of secondary antibody deficiency, specifically focusing on therapies targeting $\mathrm{B}$ cells, alongside recent advances in screening, biomarkers of risk for the development of secondary antibody deficiency, diagnosis, monitoring, and management.

Keywords: secondary antibody deficiency, chronic lymphocytic leukemia, lymphoma, multiple myeloma, solid organ transplant, immunoglobulin replacement (IgRT)

\section{INTRODUCTION}

Antibody deficiencies, a subset of immunodeficiencies, are classified as primary or secondary in etiology. Primary antibody deficiency (PAD) refers to a heterogeneous group of genetic disorders characterized by an intrinsic impairment in antibody production or function $(1,2)$. The prevalence of PAD has been estimated to be around 1 in 2,000 children, 1 in 1,200 individuals of any age, and 1 in 600 households in the United States ( 150,000-360,000 patients) (3). Secondary immunodeficiencies (SID) on a worldwide scale occur as a consequence of an extrinsic influences, such as malnutrition, human immunodeficiency virus (HIV) infection, malaria, neutropenia, or as a side effect of certain medications (4). Secondary antibody deficiency, a type of SID, is often multifactorial in etiology, related to both the underlying condition and its treatment, including 
a growing range of treatments targeting B cells. Secondary antibody deficiency occurs across a broad wide disease spectrum, and is therefore of importance to clinicians in both primary and secondary care. Secondary antibody deficiencies are can be estimated to be 30 -fold more common than PADs, but unlike PADs are sometimes reversible if the underlying cause is resolved (4). There are several types of secondary antibody deficiency, the most common being disease-related secondary antibody deficiency, caused by hematologic malignancies such as chronic lymphocytic leukemia (CLL), lymphoma, and multiple myeloma (MM). Other types of secondary antibody deficiency include iatrogenic secondary antibody deficiency as a side effect of specific therapies designed to target B cells directly as well as non$B$ cell specific therapies or processes which nonetheless impact on $\mathrm{B}$ cells or antibodies including conventional immunosuppressive agents (e.g., cyclophosphamide, methotrexate, mycophenolate mofetil) steroids, radiation therapy, solid organ transplantation (SOT), and secondary antibody deficiency related to proteinlosing states due to renal, gastrointestinal, or cutaneous loss (Figure 1) (2, 4-6). Patients with secondary antibody deficiency due to renal or gastrointestinal loss of IgG often have retained specific antibody production and hence may have a lower infection risk when compared to a failure to produce antibodies (2). The removal of antibodies by plasma exchange or blockade of the neonatal $\mathrm{Fc}$ receptor $(\mathrm{FcRn})$ is also likely to confer a lower risk of infection than deficiencies in antibody production (7-10).

The spectrum of clinical impact of secondary antibody deficiency may range from a rather limited infection susceptibility to a more significant burden characterized by predominantly sinopulmonary recurrent, chronic, systemic, or complicated infections or even including opportunistic infections, such as cytomegalovirus (CMV) in transplantation (5). Although secondary antibody deficiency is a recognized phenomenon, there are only a limited number of studies addressing the incidence and clinical importance of this disorder (11) and treatment outcomes have not been fully explored.

The prevalence of secondary antibody deficiency, which is estimated to be 30 times more common than PAD (12-15), is increasing for a number of reasons. Growth in new therapies for autoimmune, inflammatory, and malignant disease, many targeting B cells, is rapid. It is being increasingly appreciated that the use of such therapies, such as rituximab, alongside highdose, and long-term steroid treatment, either in combination with other treatments, sequentially over time or as maintenance therapies may contribute to the increased development of iatrogenic secondary antibody deficiency $(5,6)$. Studies report an increased risk of infection with B cell-targeting drugs such as rituximab or ibrutinib, and with long-term steroid treatment $(16,17)$. It is becoming increasingly important to address the unmet needs in this growing patient population, including risk factors for the development of secondary antibody deficiency, improved screening, monitoring, and treatment strategies.

The clinical management of secondary antibody deficiency involves a range of potential interventions based on a careful clinical and laboratory assessment of risk and may include patient education, prompt access to emergency antibiotics,

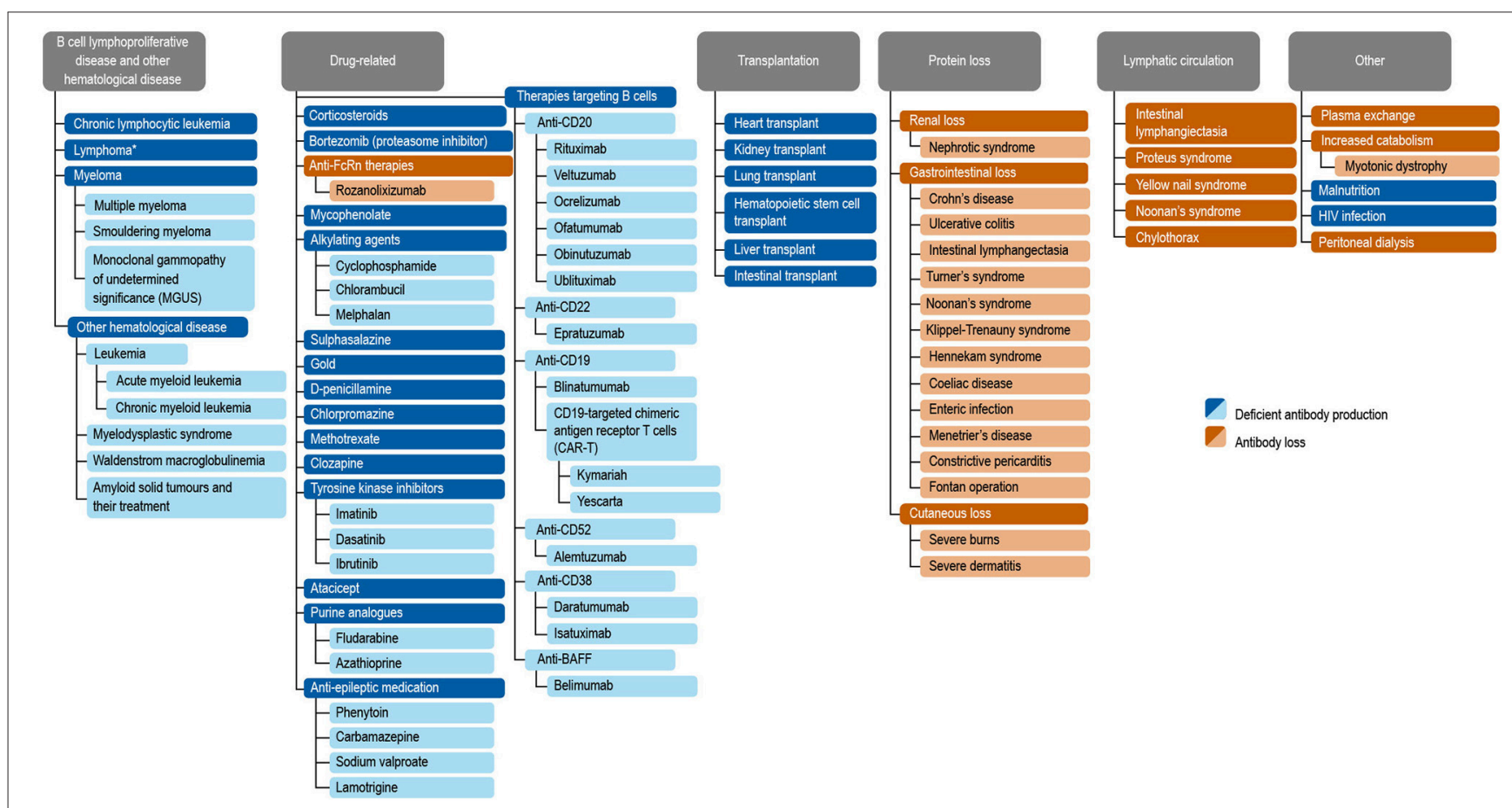

FIGURE 1 | Common causes of secondary antibody deficiency (26), (5), (251), (255), (256), (242), (6), (144), (7), (165), (70), (242), (18), (168), (244), (134), (141), (135), (139), (133), (155), (245), (147), (138), (38), (162), (124), (163), (246), (174), (233), (253), (257), (247), (252), (249), (250), (10), (254). Reproduced with the permission of the copyright holder John Wiley \& Sons Inc (5). *Including non-Hodgkin's lymphoma, Hodgkin's Lymphoma, diffuse large B cell lymphoma, follicular lymphoma, mantle cell lymphoma, marginal zone lymphoma, and Burkitt's lymphoma (5). 


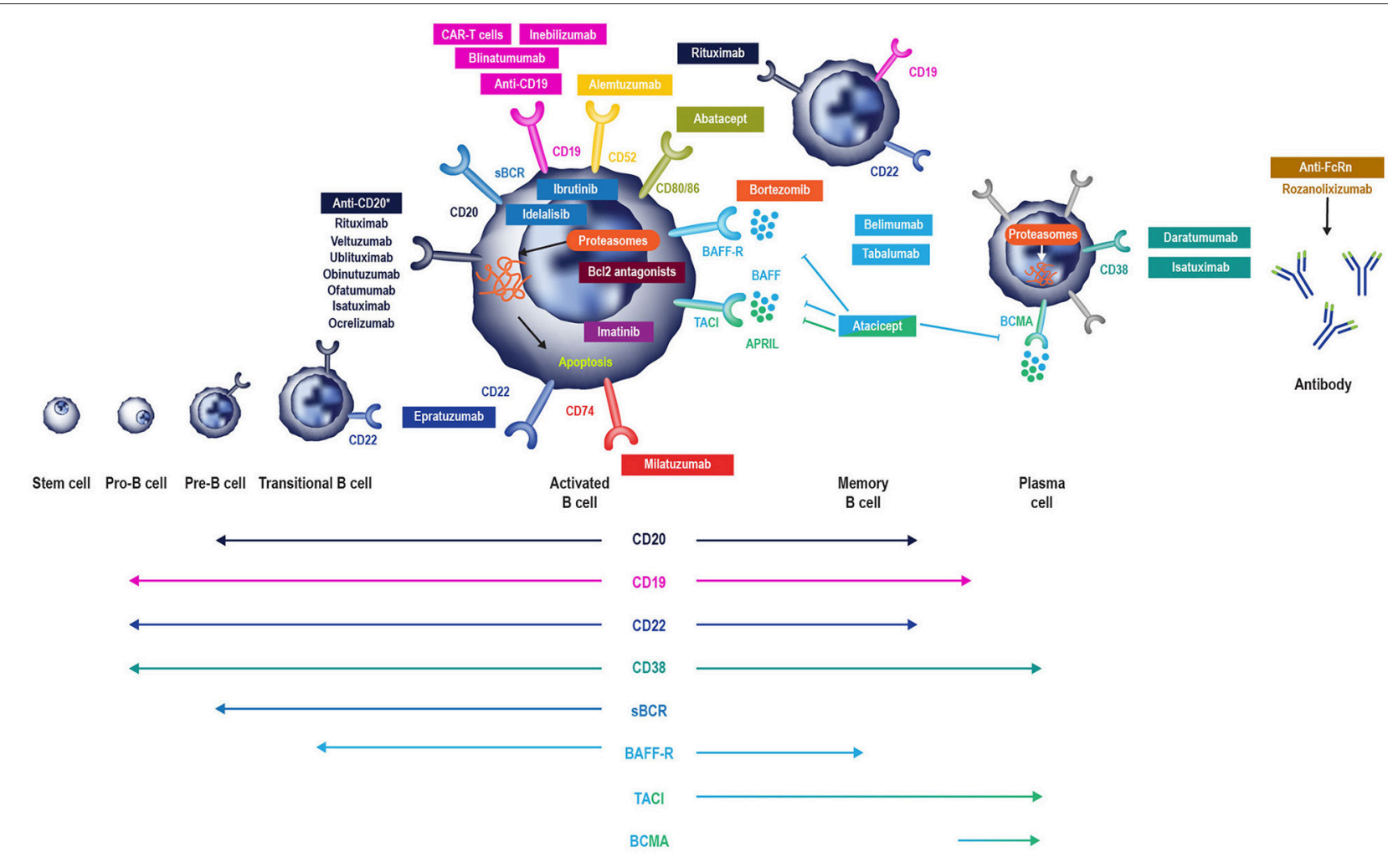

FIGURE 2 | B cell-specific chemotherapeutic causes of secondary antibody deficiency. Reproduced with the permission of the copyright holder The Royal College of Physicians (2). *Anti-CD20 compounds conjugated to other drugs are also in development. APRIL, a proliferation inducing ligand; BAFF(-R), B-cell activating factor (receptor); Bcl2, B cell lymphoma 2; BCMA, B-cell maturation antigen; (s)BCR, (surface) B cell receptor; TACl, transmembrane activator, and calcium modulator.

prophylactic antibiotic treatment, vaccination, and reducing immunosuppression or treating the underlying cause in the small proportion where this is possible. A trial of immunoglobulin replacement therapy (IgRT) may be warranted for selected patients with low immunoglobulin $\mathrm{G}(\mathrm{IgG} ;<4 \mathrm{~g} / \mathrm{L})$ who continue to suffer recurrent infections despite prophylactic antibiotics and who fail to respond to vaccination. Available studies report IgRT as an effective treatment for reducing the rate of serious infections in patients with CLL or MM (17-19). Recent market research of secondary specialty pharmacy data from the United States, France, the United Kingdom, Germany, Spain, Australia and Canada reported that the major secondary antibody deficiency indications leading to IgRT usage were CLL and MM, which represent $39.2-54.9 \%$ of all patients with secondary antibody deficiency receiving IgRT (20).

In this review, we discuss the causes, diagnosis, and management of secondary antibody deficiency, specifically focusing on new developments in agents targeting B cells (Figures 1, 2).

\section{CAUSES OF SECONDARY ANTIBODY DEFICIENCY}

\section{CLL, MM, and Lymphoma}

Hematological malignancies such as CLL, MM, and lymphoma are commonly associated with hypogammaglobulinemia. CLL is one of the most common leukemias, with an annual incidence of 4.7 in 100,000 (15). Infection frequency in CLL correlates positively with hypogammaglobulinemia, which is present in up to $85 \%$ of these patients and contributes substantially to morbidity and mortality, with infection-related deaths in 25$50 \%$ of patients (13). The prevalence of hypogammaglobulinemia in CLL is more pronounced with prolonged disease duration and advanced-stage disease and correlates with patient age and comorbidities (13).

Multiple myeloma has an annual incidence of 6.6 cases per 100,000 persons in the United States (14). Secondary antibody deficiency is also common in MM, occurring in $45-83 \%$ of patients with smoldering $\mathrm{MM}$ at some point during the disease course (21). Infections in such patients are predominantly caused by encapsulated bacteria, such as certain strains of Haemophilus influenzae, however overall susceptibility is wide and includes Clostridium difficile and Escherichia coli, Staphylococcus aureus, and fungal and viral infections, such as Varicella Zoster virus $(\mathrm{VZV})(6,22)$. One study of more than 3,000 patients with MM demonstrated that infection was responsible for $45 \%$ of deaths within 6 months of diagnosis. Respiratory tract infections (RTIs) are noted most frequently, with pneumonia, septicemia, and urinary tract infections (UTIs) also occurring commonly in this patient population $(6,23)$. The hazard ratios of developing pneumonia, septicemia, or meningitis have been shown to be 7.7-, 15.6-, and 16.6-fold, respectively, in patients with MM, compared with population-based agematched controls (23). 
The mechanisms of antibody deficiency and hence infection susceptibility in CLL are multifactorial. Defective function of the non-clonal CD5-negative $\mathrm{B}$ cells and direct suppression of $\mathrm{CD}^{+} 5^{+}$bone marrow plasma cells through CD95L/CD95 interactions between plasma cells and CLL-B cells are postulated to cause a B cell defect (13). Regulatory abnormalities in $\mathrm{T}$ cells (e.g., decreased helper $\mathrm{T}$ cell or increased $\mathrm{T}$ suppressor cell activity) (24) and dysfunctional dendritic cells or natural killer cells may also contribute to the infection burden associated with hypogammaglobulinemia in CLL and MM (2, 6, 13). There is also evidence that CLL-B cells replace normal $B$ cells (25), thereby inhibiting the function of non-malignant $B$ cells by subverting $T$ cell help in the pseudofollicle (26), and may also directly suppress IgG production by bone marrow plasma cells (27). Additional B cellindependent risk factors, such as neutropenia, and significant renal dysfunction can be both disease related and a consequence of treatment. Furthermore, renal disease can act as a cofactor in increasing infection burden not only in CLL and MM but in other settings where there is significant renal impairment $(28,29)$.

\section{Therapeutic Agents That Can Cause Secondary Antibody Deficiency}

Although CLL and MM can themselves result in secondary antibody deficiency, there is also an additional risk of iatrogenic secondary antibody deficiency posed by the therapies used to treat these, and other conditions (Table 1). Therapies for CLL and MM often suppress immune function, increasing the likelihood of clinically significant infection primarily depending on the actions of the drug, its dose, the duration of treatment, and the stage of CLL (123). According to the market research survey mentioned above, iatrogenic secondary antibody deficiency accounted for $12.8-22.1 \%$ of all secondary antibody deficiency cases worldwide (20).

Drugs given as chemotherapy include alkylating agents (cyclophosphamide, chlorambucil, bendamustine), corticosteroids, and purine analogs (fludarabine, cladribine, and thiopurines) (6). Treatment with alkylating agents is known to be associated with the development of myelosuppression, during which common infections include pneumonia and bacteremia, caused predominantly by $S$. aureus, Streptococcus pneumoniae, H. influenzae, and Klebsiella pneumoniae (6). Purine analogs and purine synthesis inhibitors (such as mycophenolate mofetil) inhibit DNA synthesis, thereby reducing $\mathrm{T}$ and $\mathrm{B}$ cell proliferation. Use of these therapies, therefore, is more commonly associated with opportunistic infections (e.g., VZV, Listeria monocytogenes, and Candida spp.) in patients with hematological malignancies (6).

It is well-known that high-dose and long-term treatment with systemic steroids exerts immunosuppressive effects on cellular immunity; however, there is a growing appreciation of the impact on antibody production. A study of the prevalence of hypogammaglobulinemia in 36 patients with giant cell arteritis and polymyalgia rheumatica on glucocorticoid therapy reported that approximately half of the patients developed IgG deficiency with less impact on IgA and IgM and a reduction in naïve B cells with relative preservation of class switched memory B cells (73).

Importantly, diagnostic findings such as this relatively IgGspecific effect of glucocorticoid therapy, can be used clinically to help determine the etiology of antibody deficiency (primary or secondary), a distinction which is diagnostically challenging (73). It is particularly difficult to determine causality of antibody deficiency following administration of therapies known to potentially cause secondary antibody deficiency, especially in situations where both the disease and the treatment used can cause secondary antibody deficiency (e.g., CLL), as well as when multiple lines of immunosuppressive therapy have been used over time $(5,73)$. In the case of heart transplantation, single center, multi-center, and metanalysis studies have demonstrated the role of immunological monitoring of humoral immunity using similar tools and cut-offs as those used in the diagnosis of PAD (124-126).

There are also diseases other than hematological malignancies that are associated with an increased risk of secondary antibody deficiency following treatment. For example, in antineutrophil cytoplasmic antibody-associated vasculitis (AAV), secondary antibody deficiency of IgG $<4 \mathrm{~g} / \mathrm{L}$ occurs commonly, presenting in $9 \%$ of patients after rituximab induction and in a further $4.6 \%$ of patients with maintenance therapy in those with low initial IgG levels (127). This degree of secondary antibody deficiency is higher than observed for the long-term combination of rituximab and methotrexate in rheumatoid arthritis, where reduced levels of $\operatorname{IgG}, \operatorname{IgA}$, and $\operatorname{IgM}$ were observed in $3.5,1.1$, and $22.4 \%$ of patients, respectively (128). It is of course difficult to determining whether this increase in the incidence of secondary antibody deficiency is clearly disease specific, but the findings do suggest that a high index of suspicion is needed in this condition in particular.

In neurology, B cell ablation is being increasingly used, for conditions including neuromyelitis optica spectrum disorders, relapsing-remitting multiple sclerosis, myasthenia gravis, autoimmune encephalitis, immune mediated peripheral neuropathies and primary angiitis of the central nervous system, with reports of secondary antibody deficiency consequent upon the use of these agents $(129,130)$. Clozapine, a drug used in treatment-resistant schizophrenia, has been associated with an increased incidence of pneumonia and death from infection. It has also recently been found to be associated with secondary antibody deficiency, as demonstrated by levels of IgG, IgA, and IgM below the reference range in $8.5 \%, 13.8 \%$, and $34 \%$ of patients, respectively (70).

\section{Newer Therapeutic Agents That Can Cause Secondary Antibody Deficiency}

While the risk of secondary antibody deficiency in patients with CLL and MM and those treated with traditional chemotherapeutic agents has been relatively well-described in older studies, there have been major therapeutic advances which have significantly influenced the risk of iatrogenic secondary antibody deficiency. Amongst these advances, of 
TABLE 1 | Reported outcomes of therapeutic agents with the potential to cause iatrogenic secondary antibody deficiency.

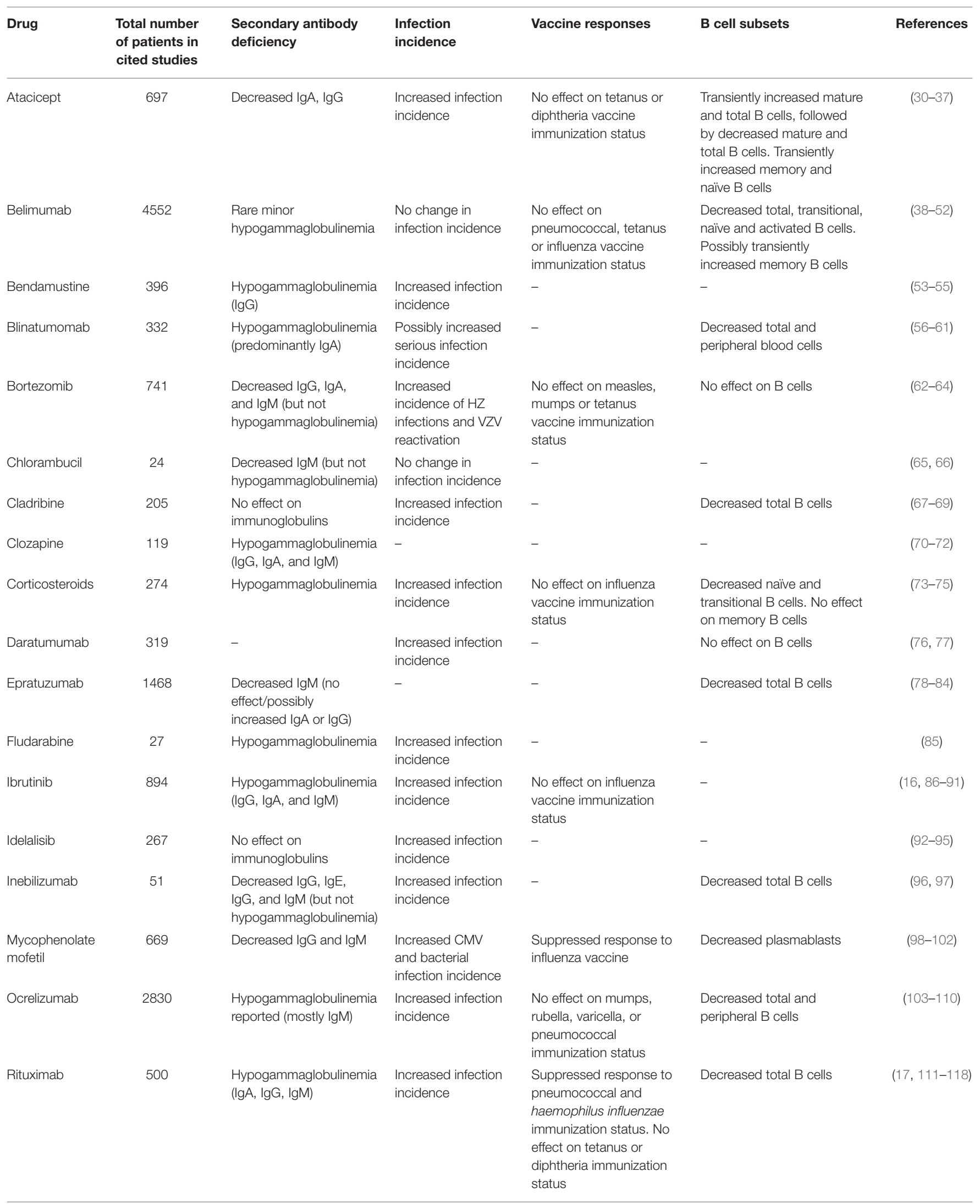


TABLE 1 | Continued

\begin{tabular}{|c|c|c|c|c|c|c|}
\hline Drug & $\begin{array}{l}\text { Total number } \\
\text { of patients in } \\
\text { cited studies }\end{array}$ & $\begin{array}{l}\text { Secondary antibody } \\
\text { deficiency }\end{array}$ & $\begin{array}{l}\text { Infection } \\
\text { incidence }\end{array}$ & Vaccine responses & B cell subsets & References \\
\hline Rozanolixizumab & 36 & $\begin{array}{l}\text { Decreased } \lg G \text { (no } \\
\text { effect on } \lg A, \lg D, \lg E \\
\text { or } \lg M \text { ) }\end{array}$ & $\begin{array}{l}\text { No change in } \\
\text { infection incidence }\end{array}$ & $\begin{array}{l}\text { No effect on tetanus or } \\
\text { influenza immunization } \\
\text { status }\end{array}$ & No effect on B cells & $(7)$ \\
\hline Thiopurines & 102 & $\begin{array}{l}\text { Decreased } \lg A, \lg G \text {, } \\
\text { and } \lg M\end{array}$ & $\begin{array}{l}\text { No change in } \\
\text { infection incidence }\end{array}$ & $\begin{array}{l}\text { No effect on } \\
\text { pneumococcal, tetanus } \\
\text { or haemophilus } \\
\text { influenzae type B } \\
\text { vaccine immunization } \\
\text { status }\end{array}$ & - & $(119-122)$ \\
\hline
\end{tabular}

particular relevance are the many new B cell targets shown in Figure $2(2,6)$. These treatments either deplete $B$ cells (anti-CD20, anti-CD52, anti-CD74, anti CD19, anti-CD22) and plasma cells (anti-CD38) or inhibit B cell survival (anti-Bcell activating factor $[\mathrm{BAFF}]$ ), impair activation (proteasome inhibitors, tyrosine kinase inhibitors) or interaction with $\mathrm{T}$ cells (anti-CD80/86) (2) and all have the potential to cause iatrogenic secondary antibody deficiency. Bruton's tyrosine kinase (BTK) inhibitors, such as ibrutinib, target BTK to inhibit $B$ cell survival and proliferation (Figure 2), and are increasingly used in CLL $(16,131,132)$, with severe infections of Grade 3 or higher reported in up to $35 \%$ of patients (132). Blinatumomab, a bispecific $\mathrm{T}$ cell engager (BiTE) antibody, crosslinks CD3 on $\mathrm{T}$ cells to CD19 on $\mathrm{B}$ cells activating endogenous $\mathrm{T}$ cells to proliferate and become cytotoxic to CD19-positive B cell targets (133) and, as such, is also expected to have the potential to cause secondary antibody deficiency. The phosphoinositide 3-kinase $\delta$ inhibitor idelalisib, approved for the treatment of CLL, follicular lymphoma, and small lymphocytic lymphoma, has been associated with increased risk of infections, including pneumonia (92). In addition to these, there is a rapidly increasing number of other new anti-B cell agents, including those targeting molecules expressed by $\mathrm{B}$ cells throughout different parts of their developmental pathway such as CD19, CD20 CD22, CD38, CD74, and proteasomes (Figure 2) (38, 96, 134-148).

Given the relatively recent development of some of these therapies, evidence for secondary antibody deficiency during their use is limited by study size, disease setting, and duration of therapy.

In the case of anti-CD19 agents, reductions in all immunoglobulin classes have been reported (although still falling within the reference range) during a small study of inebilizumab in multiple sclerosis (96) and hypogammaglobulinemia was reported in $6 \%$ of patients treated with blinatumomab (149). There is more limited information on the incidence of secondary antibody deficiency for the anti-CD20 antibodies ofatumumab and ocrelizumab, however an increase in infection incidence has reported for ocrelizumab (150).

Results thus far have shown a reduction in IgM but not IgG for the anti-CD22 antibody epratuzumab (78), and a potential increase in the incidence of VZV infection with the anti-CD38 agent daratumumab which targets plasma cells (151). The proteasome inhibitor bortezomib has been associated with increased incidence of VZV infection, in addition to herpes simplex virus infection (29). For the anti-CD74 agent milatuzumab, currently in development, there are as yet no published data related to secondary antibody deficiency or risk of infection, and for all of these more recently-developed agents, longer-term studies will be needed to define the degree of impact on immunoglobulins in different disease settings.

Interestingly, anti-BAFF therapy with belimumab has not been associated with a reduction in IgG, pneumococcal antibodies or an increase in infection, and IgM memory B cells have been shown to be reduced while class switched memory B cells were preserved $(38,39)$. For the transmembrane activator and calcium-modulating cyclophilin ligand interactorIg fusion protein atacicept, used in systemic lupus erythematous and rheumatoid arthritis, a reduction in all immunoglobulins has been reported, although this was not linked to infection (152-154).

A good example of increased potency of some of the new therapies are chimeric antigen receptor (CAR)- $\mathrm{T}$ cells with synthetic, engineered receptors targeting B cells (e.g., anti-CD19) which are used for the treatment of hematological malignancies (155-157). These engineered $\mathrm{T}$ cells can proliferate and retain effector functions of the activated $\mathrm{T}$ cells. The likelihood of iatrogenic secondary antibody deficiency with CAR-T therapy is so high that B cell depletion is acknowledged as an "expected on-target result" which may require the use of IgRT (155).

\section{Future Therapeutic Agents That Could Cause latrogenic Secondary Antibody Deficiency}

Novel therapeutic strategies continue to be identified. The tetravalent bispecific anti-CD19/CD3 T and Ab tandem diabody AFM11, which consists only of Fv domains, with two binding sites for CD19 on B cells and two for CD3 on T cells, was designed to exhibit higher potency than blinatumomab owing to the bivalent binding of the $\mathrm{Fv}$ domains to both $\mathrm{B}$ and $\mathrm{T}$ cells, resulting in enhanced B cell lysis (158). These immune cell-recruiting bispecific antibodies harness the cytotoxic potency 
of endogenous $\mathrm{T}$ cells (or in some cases NK cells) to kill both malignant and normal B cells (158).

Yet other treatments are becoming available that may be able to treat their target diseases not by interfering with antibody production but by removing pathogenic autoantibodies by reduction of their half-life. Rozanolixizumab, for example, is an anti- FcRn monoclonal antibody (Figure 2) (7). FcRn salvages and recycles plasma IgG autoantibodies, thus extending their lifespan $(7,159)$. Selective inhibition of FcRn, and hence the salvage pathway, offers a new approach for the removal of pathogenic IgG autoantibodies in the treatment of autoantibodymediated disease. While pre-clinical and clinical studies of rozanolixizumab have not shown an increase in the incidence of infection (7), long-term studies and close monitoring will be needed. As mentioned above, the risk of infection appears lower where there is removal (plasma exchange, anti-FcRn mAb) or loss (protein-losing enteropathy or renal loss) of functionally normal antibody rather than a production failure. This may translate into a lower infection risk with anti-FcRn therapies; however, longterm data will be required and it would seem prudent to optimize protection from infection by ensuring appropriate vaccination prior to commencement of therapy.

\section{Solid Organ Transplantation (SOT)}

In addition to the risks associated with hematological malignancy and immunosuppressive drugs, there are also other, perhaps less well-recognized situations in which patients are at risk of developing secondary antibody deficiency. Solid organ transplantations (SOTs) are now routine surgical procedures for treating organ dysfunction, with an estimated 119,873 SOTs performed worldwide in 2014, and 30,970 in the US alone in 2015 (160). Patients receiving SOT are given immunosuppressive drugs before, during, and after transplantation to prevent organ rejection (161). While immunosuppressive drugs are recognized as a common cause of secondary antibody deficiency, there are additional risks in SOT including the transplantation procedures themselves as well as other interventions, such as the use of ventricular assist devices in heart recipients or extracorporeal membrane oxygenation in heart and lung recipients, which are also associated with the occurrence of SOT-related secondary antibody deficiency $(162,163)$. Several studies have shown a high prevalence of hypogammaglobulinemia after SOT, particularly after heart, lung, and kidney transplantation, with an associated increased risk for infections $(124,164)$. Infections, most frequently non-CMV infections, are reported to be the leading cause of death during the first year after heart or lung transplantation (Figure 3) (163). In one meta-analysis of 669 SOT patients, $15 \%$ developed severe hypogammaglobulinemia $(\operatorname{IgG}<4 \mathrm{~g} / \mathrm{L})$ during their first year post transplantation (124). This study also reported a 4.8-fold increase in respiratory infections, a 2.4-fold increase in CMV infections, and an 8fold increase in aspergillus infections (3.7-fold increase in other fungal infections) when severe hypogammaglobulinemia was present (124). Furthermore, two other groups have also reported an increased incidence of opportunistic infections in heart transplantation with hypogammaglobulinemia, particularly

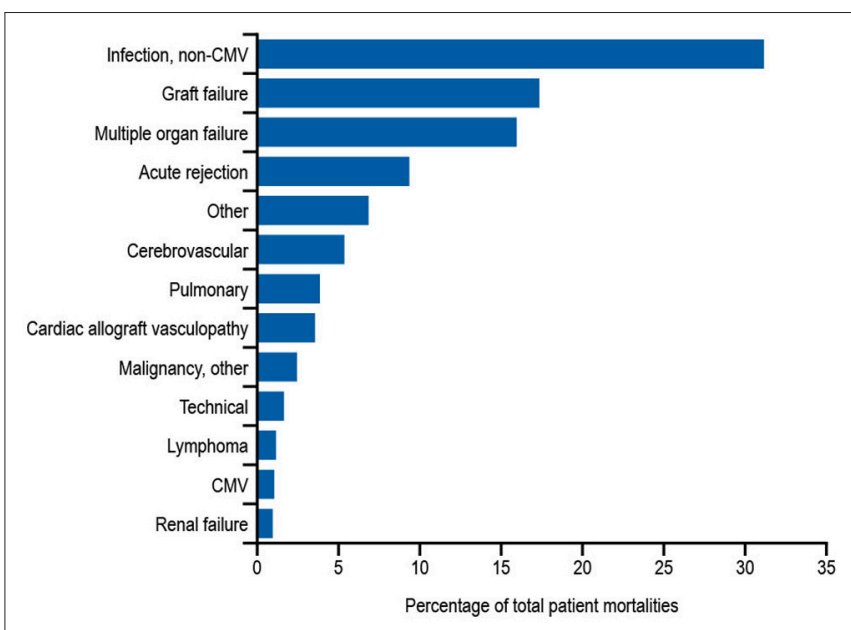

FIGURE 3 | Relative incidence of leading causes of death (31 days to 1 year) in adults receiving heart transplants Jan 1994-June 2016. Developed using data from The International Society for Heart \& Lung Transplantation, (2017) (163); CMV, cytomegalovirus.

CMV viremia $(126,162)$. In addition, lower levels of antipneumococcal antibodies are a risk factor for development of severe bacterial infections in heart recipients (165).

\section{DIAGNOSIS}

The prompt diagnosis of secondary antibody deficiency is key in reducing infection burden and is dependent on appropriate screening and an appreciation of risk factors for secondary antibody deficiency development. Monitoring of patients at risk of developing secondary antibody deficiency, such as patients receiving conventional immunosuppressive drugs or newer, more targeted therapies, could help in identifying these patients before they develop a serious infection. For rituximab, which is known to be associated with the development of secondary antibody deficiency, the risks for an individual are increased with low baseline IgG prior to rituximab initiation; exposure to prior therapies, such as cyclophosphamide, steroids, and purine analogs, purine synthesis inhibitors (mycophenolate mofetil), or the use of combination therapy or granulocytecolony stimulating factor (166). Furthermore, the single use of rituximab rarely causes hypogammaglobulinemia, yet there is an increased risk for patients undergoing maintenance or multiple cycles of treatment. Finally, patients with comorbidities, such as chronic lung or heart disease and extra-articular rheumatoid arthritis, have higher instances of hypogammaglobulinemia, with more infections occurring when IgG is low for longer than 6 months (166). Although there may also be particular non-hematological diseases which have higher rates of secondary antibody deficiency, such as AAV and neuromyelitis optica spectrum disease, the caveat remains that it is difficult to separate the effect of treatment from disease.

The evaluation of patients at high risk or with suspected hypogammaglobulinemia should include quantitative serum Ig 
concentrations and analysis of vaccination responses if initial specific antibody levels are found to be low. High-risk patients may merit annual immunoglobulin measurements to screen for the development of secondary antibody deficiency. It is likely that in some cases it will be helpful to determine levels and reconstitution of $\mathrm{B}$ cell numbers, including the preservation of class-switched memory B cell and plasma cell compartments. For example, in some settings the measurement of the return of class-switched memory B cells is already being used to determine the timing of retreatment with rituximab to reduce the cumulative rituximab dose without apparent loss of efficacy (167). In addition, complete blood count will assist in identifying additional risk factors such as neutropenia, lymphopenia, or lymphocytosis $(2,168)$.

Some treatment-specific screening or monitoring programs have been introduced to mitigate infection-related risk; for example, the Pharmacovigilance Risk Assessment Committee of the EMA recommends that patients receiving idelalisib should be informed about the risk of serious and/or fatal infections, given prophylaxis for Pneumocystis jirovecii pneumonia, and monitored for signs and symptoms of respiratory infections throughout the idelalisib treatment. Regular clinical and laboratory screening for CMV infection should also be conducted and absolute neutrophil counts monitored in all patients at least every 2 weeks for the first 6 months of treatment. In the case of clozapine, the Clozapine Risk Evaluation and Mitigation Strategy (REMS) monitoring scheme has been established to reduce the risks associated with neutropenia, however antibody monitoring is not currently part of the scheme (169).

In patients receiving SOT, several biomarkers have been shown to be useful in stratifying the risk of developing SOTrelated secondary antibody deficiency and associated infections. For example, in patients receiving a heart transplantation, IgG levels of $<10 \mathrm{~g} / \mathrm{L}$ prior to transplantation may predict high frequency of bacterial infections, therefore suggesting that monitoring of IgG levels prior to transplantation may be important in predicting secondary antibody deficiency and subsequent infection. Similarly, low levels of class-switched memory B cells may also act as pre-heart transplantation biomarkers. Several post-heart transplantation biomarkers, such as low peripheral lymphocyte populations, may also help in predicting infections. For example, low anti-CD8 response to CMV antigens assessed by enzyme-linked immune absorbent spot (ELISPOT) or flow cytometry can be used as a biomarker for the risk of developing CMV infection and disease (170). Other prospective post-SOT biomarkers include complement components (e.g., C3 and C4), owing to their effector functions in the innate and adaptive humoral immune responses (171). The classic in vitro hemolytic assays utilized for assessing classical and alternative complement pathway function are complex, susceptible to pre-analytical sample handling issues, and time consuming. Nephelometry represents a convenient option for the measurement of certain complement components in serum (172). As complement activation is responsible for the clearance of encapsulated bacteria, hypocomplementemia may result in increased susceptibility to infection (171). It has been shown that hypocomplementemia is an indicator of bacterial infection risk in patients following kidney transplantation (173), with similar findings reported for liver (174) and heart (175) recipients. The combination of low IgG and low C3 in serum can be particularly detrimental in SOT patients. One multivariate analysis demonstrated that hypogammaglobulinemia $(\operatorname{IgG}<6 \mathrm{~g} / \mathrm{L})$ or $\mathrm{C} 3$ hypocomplementemia $(\mathrm{C} 3<80 \mathrm{mg} / \mathrm{dL}$ ) on Day 7 post heart transplantation were independent risk factors for infection (especially bacterial infections) and CMV disease (125). However, the combination of both was more strongly associated with the risk of infections than either hypogammaglobulinemia or C3 hypocomplementemia alone. Furthermore, on Day 7, low antiCMV antibody titers and low anti-pneumococcal polysaccharide antibody concentrations as biomarkers of impaired specific antibody responses were independent predictors of CMV disease and bacterial infections, respectively (125). These biomarkers can be used to identify patients at high risk who may benefit from IgRT post heart transplantation (Table 2, Figure 4). The evaluation of CMV IgG serology of donor and recipient is a classic evaluation to identify the risk of CMV disease after SOT (170). CMV seronegative recipients receiving an allograft from a CMV seropositive donor are considered to be at higher risk of having this complication than other serological combinations. More recently, the assessment of $\mathrm{CD} 8$ responses to $\mathrm{CMV}$ antigens has also been introduced to evaluate the risk of CMV disease in SOT (170).

An interesting aspect of the management of heart and other SOT recipients is that vaccination is not common practice during the first months after transplantation, when the majority of severe infections occur, because the specific antibody response after immunization in this period has been demonstrated to be low (187). This should be taken into account at the time of diagnosing secondary antibody deficiency in this setting. Moreover, the titers of anti-pneumococcal or anti-CMV antibodies gradually decline during the first year after transplantation as a result of the immunosuppressive therapy, leaving the patients exposed to infection $(165,178,188)$.

\section{TREATMENT}

While removal of the underlying causative factor would be the preferred option for treating secondary antibody deficiency, (e.g., as a consequence of the removal of an abnormal section of bowel in protein-losing enteropathies or reduction of immunosuppression post hematopoietic stem cell transplantation [HSCT]) this is overall rarely possible, particularly when treatment cannot be easily avoided as is the case with SOT, CLL, MM, or lymphoma. Indeed, in the case of HSCT, this may also itself lead to secondary antibody deficiency and subsequent infection, the risks of which are increased by the presence of graft vs. host disease (GvHD) in these patients $(189,190)$. While the mechanism of GvHDmediated secondary antibody deficiency is not fully understood, it is thought to potentially delay B cell engraftment, leading to B cell lymphopenia, and to delay/prevent B cell maturation and memory development, markedly decreasing memory and switched memory B cells $(191,192)$. 


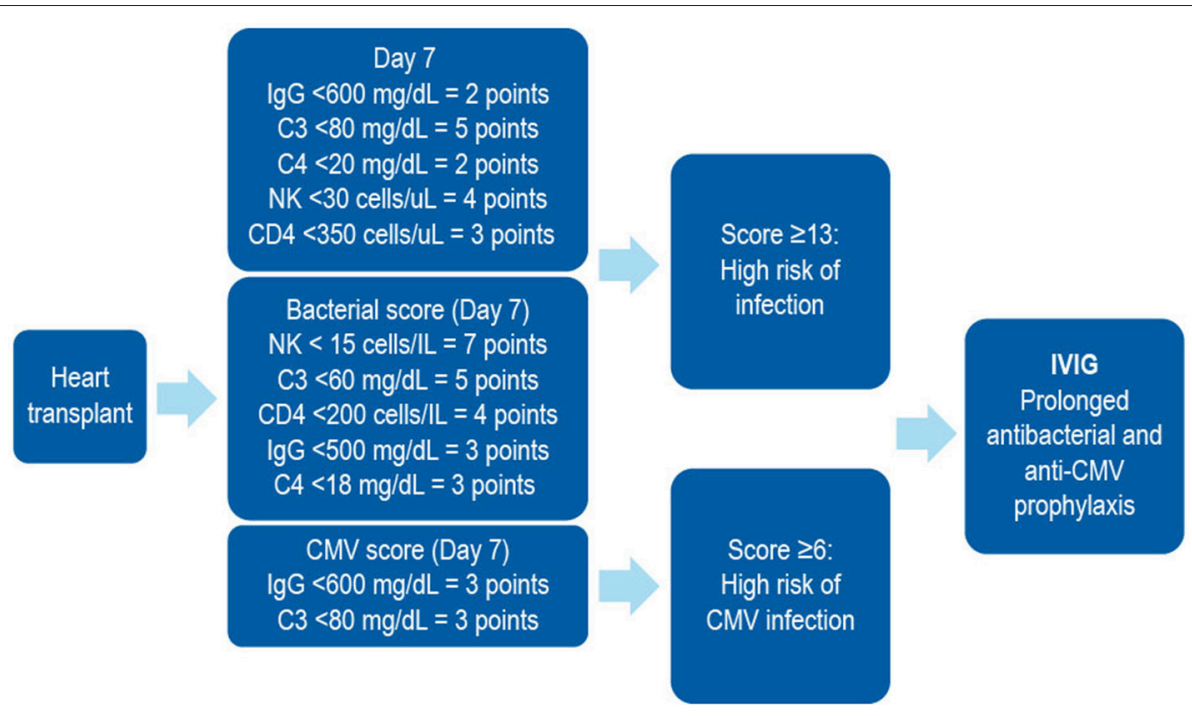

FIGURE 4 | A combined immunodeficiency profile identifies risk of severe infection in heart transplant recipients. Developed using data from Sarmiento et al. (186). C, complement; CD, cluster of differentiation; CMV, cytomegalovirus; IVIG, intravenous immunoglobulin; NK, natural killer.

In hematological malignancy, supportive treatments including prophylactic vaccination (with non-live vaccines), antibiotics and/or IgRT may be considered for patients with secondary antibody deficiency. A careful review of the patient's history, assessment of the risk factors for developing secondary antibody deficiency and evaluation of serum IgG levels and specific antibody levels is key to the diagnosis and treatment. Immunologists often have greater experience in managing PAD than secondary antibody deficiency, and it is likely that the clinical and laboratory assessments used in this setting would also be of utility in secondary antibody deficiency. However, there is limited evidence in the literature, particularly relating to the increasing number of newer therapies, to guide clinical management of secondary antibody deficiency.

\section{Prophylactic Vaccination}

Prophylactic non-live vaccinations such as influenza are recommended for patients with secondary antibody deficiency, as is the case in PAD. Although the antibody response may not be optimal, some helpful protection via antibodies and $\mathrm{T}$ cell immunity may still be achieved; thus, influenza vaccination is advised. Live vaccination is generally not recommended in patients with secondary antibody deficiency (although individual assessment and decisions are warranted). Instead, component or inactivated vaccines should be used. Studies suggest that vaccination at an early stage (before initiation of chemotherapy and the onset of hypogammaglobulinemia) may be more helpful in generating immunological memory when specific antibody levels are low (123). In addition, evaluation of post-vaccinationspecific antibody levels can be beneficial both therapeutically (if protective levels are achieved) and in stratification of risk before and following treatment. Vaccination against S. pneumoniae and $H$. influenza is recommended in patients with CLL; however, the protective effect of these vaccines may be variable, emphasizing the importance of ongoing immunological assessment and individualization of care (6). In a UK-based study of patients with MM, 61\% (26/43) showed a suboptimal response to S. pneumoniae vaccination, whereas $75 \%$ (33/46) showed a response to $H$. influenzae type $\mathrm{B}$ vaccination comparable with those in the healthy adult UK population. The European Myeloma Network guidelines (193) suggest that "vaccination against influenza virus is appropriate and is recommended for both patients and their contacts. Moreover, vaccination against Streptococcus pneumoniae and Haemophilus influenzae is recommended, but efficacy for all vaccines is not guaranteed, due to suboptimal immune response (grade 1C). In general, live vaccines should be avoided in myeloma patients (grade 2C)" (193).

The Infectious Diseases Society of America has recommended the routine use of inactivated vaccines in patients with MM unless they are actively receiving chemotherapy or monoclonal antibody (194). The Advisory Committee for Immunization Practices recommends that patients with MM and SOT should receive vaccination with pneumococcal conjugate vaccine at diagnosis followed by revaccination more than 8 weeks later (195). Recent MM guidelines from the National Comprehensive Cancer Network do not include specific recommendations for vaccination, but do note to "consider Pneumovax and influenza vaccine" (196).

In terms of pre-transplantation vaccination schedules, it is suggested that primary immunizations should be given as soon as possible before transplantation (197). Data from a study of pediatric patients showed that vaccination prior to transplantation was effective in reducing the incidence of Varicella Zoster virus infection from 45-12\% (198). Guidelines for vaccination of SOT recipients recommend vaccination against S. pneumoniae and H. influenzae before transplantation (197, 199). As mentioned, post-transplantation, anti-pneumococcal 
TABLE 2 | Biomarkers used following heart transplantation.

\begin{tabular}{|c|c|c|c|}
\hline Organ & $\begin{array}{l}\text { Biomarker } \\
\text { (post HT) }\end{array}$ & Outcome & References \\
\hline Heart & $\operatorname{lgG}<3.5 \mathrm{~g} / \mathrm{L}$ & Opportunistic infection & (162) \\
\hline Heart & $\lg G<3.1 \mathrm{~g} / \mathrm{L}$ & Opportunistic infection & (176) \\
\hline Heart & $\lg G<6 \mathrm{~g} / \mathrm{L}$ & $\begin{array}{l}\text { Bacterial, CMV } \\
\text { infection }\end{array}$ & (126) \\
\hline Heart & $\lg G<7 \mathrm{~g} / \mathrm{L}$ & $\begin{array}{l}\text { Bacterial, CMV } \\
\text { infection }\end{array}$ & (165) \\
\hline Heart & $\lg G<4 \mathrm{~g} / \mathrm{L}$ & Clostridium difficile & $(177)$ \\
\hline Heart & $\lg G<5 \mathrm{~g} / \mathrm{L}$ & CMV disease & (178) \\
\hline Heart & Low lgG2 & Overall infection & (175) \\
\hline Heart & $\begin{array}{l}\text { anti-PPS }<5 \\
\mathrm{mg} / \mathrm{dL}\end{array}$ & Bacterial infection & (165) \\
\hline Paed heart & Low anti-PPS & Not done & $(179,180)$ \\
\hline Heart & $\begin{array}{l}\text { Low anti-CMV } \\
\text { titres }\end{array}$ & CMV infection & $(178,181,182)$ \\
\hline Heart & $\mathrm{C} 3<80 \mathrm{mg} / \mathrm{dL}$ & Overall infection & $\begin{array}{l}\text { (183) First } \\
\text { proposal of an } \\
\text { immunological } \\
\text { score }\end{array}$ \\
\hline Heart & $\begin{array}{l}\mathrm{NK}<30 \\
\text { cells/uL }\end{array}$ & & \\
\hline Heart & $\begin{array}{l}\text { CD } 4<350 \\
\text { cells/uL }\end{array}$ & & \\
\hline Heart & $\begin{array}{l}\text { Low anti-CD8 } \\
\text { response to } \\
\text { CMV }\end{array}$ & CMV infection & $(183-185)$ \\
\hline
\end{tabular}

C3, complement component 3; CD, cluster of differentiation; CMV, cytomegalovirus; $H T$, heart transplant; IgG, immunoglobulin; NK, natural killer; PPS, pneumococcal polysaccharide.

antibody titers have been shown to significantly decrease in kidney (188) and lung transplant recipients (200). Questions remain regarding the utility and timing of vaccination in secondary antibody deficiency and further studies are needed (6).

While it is generally accepted that inactivated vaccines can be administered in patients with secondary antibody deficiency, many vaccinations are not required for those patients receiving IgRT, as protective levels of antibodies are already present in the IgRT preparations and should offer some protection against a range of infectious diseases $(201,202)$. Influenza vaccination is an exception, as these vaccines are reformulated annually to reflect changes in the antigenic composition of the influenza virus and protection from IgRT is therefore less likely. However, even if the antibody response post vaccination is suboptimal, patients with PAD and also secondary antibody deficiency may benefit from the $\mathrm{T}$ cell-mediated responses $(112,203)$. Live vaccines are generally not recommended in the context of significant immunodeficiency and in patients receiving IgRT may also be less effective (204).

\section{Prophylactic Antibiotics}

Treatment of secondary antibody deficiency with prophylactic antibiotics is the recommended first-line therapy in CLL (205) and during periods of neutropenia in patients undergoing chemotherapy or other immunocompromising treatments (11).
Antibiotic therapy should take into account the previous culture and sensitivity results as well as any allergies, tolerance, and the likelihood of Pseudomonas or macrolide-resistant H. influenzae infection. In the event of a breakthrough infection, if there has been no or limited response to a back-up course of antibiotics and a second course of different antibiotics, then intravenous antibiotic (IVAB) treatment should be considered. Prophylactic and back-up antibiotics should be of different classes (e.g., macrolide and penicillin class), rather than simply increasing the dose of the existing prophylactic regimen. Monitoring (e.g., electrocardiogram) and additional patient information (e.g., regarding the development of tinnitus) may be needed for those on long-term macrolides. There are many potential antibiotic options and the examples shown in Table 3 are illustrative, with individual decisions being made on clinical grounds and local prescribing policy. Nebulized antibiotics and intermittent IVAB are options that are used mainly for severe bronchiectasis and pseudomonal colonization (Table 3).

\section{Current Use of IgG}

Many studies have demonstrated decreased infection incidence in patients with CLL treated with intravenous IgG (IVIG; Table 4). The beneficial effect of IVIG was demonstrated in a randomized, controlled, double-blind clinical trial conducted by the Cooperative Group for the Study of Immunoglobulin, where use of IVIG was associated with lower incidence of bacterial infections and longer time during which patients were free of serious bacterial infections compared with patients not receiving IVIG (206). A subsequent double-blind crossover follow-up study confirmed that maintenance on IgG results in reduction of the infection incidence (210). Later, another double-blind crossover study compared two doses of IVIG (250 and $500 \mathrm{mg} / \mathrm{kg}$ ) over a year, suggesting a significant difference in the incidence of bacterial infections between doses (208). These promising results prompted a consensus statement supporting the use of IVIG in patients with CLL with hypogammaglobulinemia and associated infections (213). However, as these studies are well over a decade old, there is a clear need for newer randomized trials in this area, particularly given the vast advances in treatment and improved survival.

Protocols for IgRT in secondary antibody deficiency vary. In clinics based in Oxford and Cardiff, UK, very similar approaches are employed where the use of IgRT and the dose administered are individualized per patient (5). In patients referred to the immunology department for recurrent and/or serious bacterial infections, immunization responses are measured 4-6 weeks after administration of protein and polysaccharide vaccines (if initial levels are low) and during the waiting period, for up to 3 months, prophylactic antibiotic use is considered. A 12month trial of IgRT (with infection monitoring) is considered in case of antibody failure and a lack of an adequate response to prophylactic antibiotics in association with a significant ongoing infection burden. Neutrophil count, serum IgG trough levels, and infection burden should be monitored regularly, and IgG use, including dosage, should be reviewed after 6 and 12 months to maintain plasma IgG trough levels sufficient for an optimal reduction in infection rate. Levels of IgG should be reviewed if 
TABLE 3 | Graded antibiotic regimens*.

\begin{tabular}{|c|c|c|c|c|}
\hline $\begin{array}{l}\text { Antibiotic } \\
\text { regimen }\end{array}$ & Dosing schedule & Additional options & Emergency plan & Example \\
\hline \multirow{3}{*}{$\begin{array}{l}\text { Intermittent } \\
\text { antibiotics }\end{array}$} & None & & Attend GP with symptoms & $\mathrm{N} / \mathrm{A}$ \\
\hline & None & & $\begin{array}{l}\text { Early use of home back-up } \\
\text { antibiotics }\end{array}$ & $\begin{array}{l}\text { Co-amoxyclav } 625 \mathrm{mg} \text { tds for } 2 \\
\text { weeks; held at home }\end{array}$ \\
\hline & $\begin{array}{l}\text { Prophylactic antibiotics } \\
\text { during the winter } \\
\text { months with home } \\
\text { rescue during the } \\
\text { summer }\end{array}$ & $\begin{array}{l}\text { Low-dose and full-dose options, } \\
\text { e.g., azithromycin } 250 \text { or } 500 \text { mg } \\
3 \text { days/week }\end{array}$ & $\begin{array}{l}\text { Early use of home back-up } \\
\text { antibiotics }\end{array}$ & $\begin{array}{l}\text { Azithromycin } 500 \text { mg } 3 \text { days/week } \\
\text { plus back-up Co-amoxyclav for } 2 \\
\text { weeks; held at home }\end{array}$ \\
\hline \multirow[t]{4}{*}{$\begin{array}{l}\text { Ongoing } \\
\text { prophylaxis }\end{array}$} & Prophylactic antibiotics & $\begin{array}{l}\text { Low-dose and full-dose options, } \\
\text { e.g., azithromycin } 250 \text { or } 500 \text { mg } \\
3 \text { days/week }\end{array}$ & $\begin{array}{l}\text { Early use of home back-up } \\
\text { antibiotics }\end{array}$ & $\begin{array}{l}\text { Azithromycin } 500 \text { mg } 3 \text { days/week } \\
\text { plus back-up Co-amoxyclav } 625 \text { mg } \\
\text { tds for } 2 \text { weeks; held at home }\end{array}$ \\
\hline & $\begin{array}{l}\text { Rotating prophylactic } \\
\text { antibiotics }\end{array}$ & & $\begin{array}{l}\text { Early use of home back-up } \\
\text { antibiotics }\end{array}$ & \\
\hline & Prophylactic antibiotics & Nebulized antibiotics & $\begin{array}{l}\text { Early use of home back-up } \\
\text { antibiotics }\end{array}$ & $\begin{array}{l}\text { Nebulized Colomycin 1-2 mega units } \\
\text { bd }\end{array}$ \\
\hline & Prophylactic antibiotics & Intermittent planned IVAB & $\begin{array}{l}\text { Early use of home back-up } \\
\text { antibiotics }\end{array}$ & $\begin{array}{l}\text { Meropenem } 2 \mathrm{~g} \text { IV tds and } \\
\text { Ceftazidime Co-amoxyclav for } 2 \\
\text { weeks; held at home }\end{array}$ \\
\hline
\end{tabular}

GP, general practitioner; IV, intravenous; IVAB, intravenous antibiotic; N/A, not available; bd, twice daily; tds, three times daily.

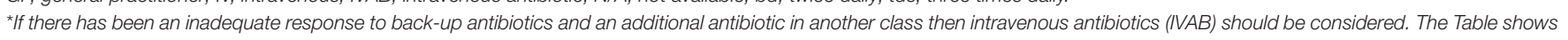
examples of antibiotic regimens and the antibiotic choice will depend on individual clinical circumstances.

TABLE 4 | Summary of evidence for the use of immunoglobulin replacement therapy in CLL.

\begin{tabular}{|c|c|c|c|c|c|c|}
\hline Reference & $\begin{array}{c}\text { Number of } \\
\text { patients }\end{array}$ & $\begin{array}{l}\text { Number of patients } \\
\text { in advanced stage* }\end{array}$ & Type of study & $\begin{array}{l}\text { Dose } \\
\text { IVIG/schedule }\end{array}$ & $\begin{array}{l}\text { Study duration } \\
\text { (months) }\end{array}$ & $\begin{array}{l}\text { Infection rate during } \\
\text { IVIG administration }\end{array}$ \\
\hline $\begin{array}{l}\text { Cooperative group } \\
\text { (206) }\end{array}$ & 81 & 32 (39.5\%) & $\begin{array}{l}\text { Controlled, randomized } \\
\text { double-blind }\end{array}$ & $\begin{array}{l}400 \mathrm{mg} / \mathrm{kg} / 21 \\
\text { days }\end{array}$ & 12 & Decreased \\
\hline $\begin{array}{l}\text { Jurlander et al. } \\
\text { (207) }\end{array}$ & 15 & 8 (53.3\%) & Not controlled, pilot & $10 \mathrm{~g} / 28$ days & 12 (mean time) & Decreased \\
\hline Chapel et al. (208) & 34 & $15(44.1 \%)$ & $\begin{array}{l}\text { Controlled, randomized } \\
\text { double-blind }\end{array}$ & $\begin{array}{l}250 \text { mg/kg vs. } 500 \\
\text { mg/kg/28 days }\end{array}$ & 12 & Decreased \\
\hline Sklenar et al. (209) & 31 & $2(6.4 \%)$ & Dose-finding & $\begin{array}{l}100-800 \mathrm{mg} / \mathrm{kg} / \\
21 \text { days }\end{array}$ & 4.5 & Decreased \\
\hline Griffiths et al. (210) & 10 & 3 (30\%) & $\begin{array}{l}\text { Controlled, randomized } \\
\text { double-blind }\end{array}$ & $\begin{array}{l}400 \mathrm{mg} / \mathrm{kg} 21 \\
\text { days }\end{array}$ & 12 & Decreased \\
\hline $\begin{array}{l}\text { Broughton et al. } \\
(211)\end{array}$ & 42 & $15(35.7 \%)$ & Randomized & $18 \mathrm{~g} / 21$ days & 12 & Decreased \\
\hline Molica et al. (212) & 30 & 25 (83.3\%) & Randomized, crossover & $\begin{array}{l}300 \mathrm{mg} / \mathrm{kg} / 28 \\
\text { days }\end{array}$ & 6 or 12 & Decreased \\
\hline
\end{tabular}

*Binet stage C or Rai III-IV.

chemotherapy is introduced during IgRT. Because patients react differently to IgRT, individualization of the treatment regimen is required (5).

One of the key factors to consider when initiating IgRT is selection of patients most likely to benefit (Figure 5). Studies suggest that patients with IgG levels $<4 \mathrm{~g} / \mathrm{L}$ and/or low levels of antibodies against encapsulated organisms with an ongoing history of recurrent bacterial infections that have not responded adequately to prophylactic antibiotics could especially benefit from IVIG $(211,215)$. Furthermore, selection of the patients should include a wider assessment of comorbidities and innate immunological abnormalities, such as neutropenia, as well as demonstrating antibody failure (exposure/test immunization). If IgRT is to be administered, a careful risk-benefit assessment should be made. This should take into consideration, for example, the reported adverse effects of IgRT, such as the rare complications of thromboembolism and hemolysis in patients with hematological malignancies $(216,217)$. Once it is established that IgRT should be offered to a patient with secondary antibody deficiency, the route [subcutaneous IgG [SCIG] or IVIG] and location (home vs. clinic) of infusions should be considered. SCIG has similar efficacy to IVIG $(218,219)$ but offers several 
potential benefits, including more stable serum IgG levels (219, 220), improved patient health-related quality of life (221), and time and cost efficiencies for both patients and healthcare providers. It has also previously been shown that the feasibility and safety of home IVIG therapy in selected CLL patients may improve patient compliance and considerably decrease costs (222). It is also recommended that patients complete at least 12 months (encompassing all 4 seasons) of IgRT in order to optimally assess the response to therapy (11). This will require ongoing review to reflect any clinical changes in the patient's underlying condition and therapy. Treatment discontinuation may be considered in stable patients with reduced incidence of infections (i.e., once treatment has restored function) to determine if IgRT is still required, or in patients where treatment does not seem to be effective in preventing infection (i.e., treatment failure) (11).

Prophylactic use of IgRT in patients post SOT has been shown to decrease the incidence of severe infection in patients with hypogammaglobulinemia $(162,223)$. It has also been shown to decrease the incidence of CMV infection in patients with hypogammaglobulinemia (224). Retrospective studies have demonstrated that addition of IVIG to antimicrobial therapy in heart transplantation recipients with secondary antibody deficiency and severe infections is associated with reconstitution of specific antibodies (anti-CMV, anti-tetanus toxoid) and lower rates of death $(183,225)$. A case series performed in heart transplantation recipients with difficult-to-control CMV infection in whom secondary antibody deficiency was found demonstrated that IVIG was associated with reduction in detectable CMV viremia and with remission of clinical symptoms of CMV disease (226).

\section{CURRENT EVIDENCE-BASED GUIDELINES FOR IGRT IN SECONDARY ANTIBODY DEFICIENCY}

The majority of guidelines recommend prophylactic antibiotics as first-line therapy for patients with CLL susceptible to serious infections (2). However, an individualized dose and duration of IgRT is also suggested where there is lack of responsiveness or failure of the antibiotics to sufficiently reduce the infection burden in such patients. Looking at specific recommendations, according to European Medicines Agency (EMA) 2018 (valid from January 2019); IVIG can be used in patients with secondary immunodeficiencies "who suffer from severe or recurrent infections, ineffective antimicrobial treatment and either proven specific antibody failure (PSAF) or serum IgG level of $<4 \mathrm{~g} / \mathrm{l}$," where PSAF is defined as "failure to mount at least a 2-fold rise in IgG antibody titer to pneumococcal polysaccharide and polypeptide antigen vaccines" (214). The dose required is stated to be probably patient dependent, but is likely to be $0.2-$ $0.4 \mathrm{~g} / \mathrm{kg}$ every 3-4 weeks (214). With regard to SCIG, EMA guidelines state that it is indicated in hypogammaglobulinemia and recurrent bacterial infections in patients with $\mathrm{MM}$ and in patients with CLL in whom prophylactic antibiotics have failed or are contraindicated (227). SCIG is also indicated for hypogammaglobulinemia in patients pre- and post-allogeneic HSCT. However, the EMA states that "the above indications would be granted as long as efficacy has been proven in primary immunodeficiency syndromes" (227).

The European Society for Medical Oncology (ESMO) guidelines, published in 2015 (228), state that "the use of prophylactic systemic IgG [in patients with CLL] does not have an impact on overall survival and is only recommended in patients with severe hypogammaglobulinemia and repeated infections [Level of evidence I, A]." They also state that "Antibiotic and antiviral prophylaxis should be used in patients with recurrent infections and/or very high risk of developing infections (e.g., pneumocystis prophylaxis with co-trimoxazole during treatment with chemoimmunotherapies based on purine analogs or bendamustine) [IV, B]" and finally, that "pneumococcal vaccination as well as seasonal influenza vaccination is recommended in early-stage CLL [IV, B]" (228).

According to The British Committee for Standards in Hematology, 2012 (205), " in the absence of recent randomized studies, recommendations for the use of immunoglobulin replacement in CLL are largely based on clinical experience and data from use in primary immunodeficiencies." Their recommended indication for the use of IgRT is "recurrent/severe infection with encapsulated bacteria despite prophylactic oral antibiotic therapy in patients with a serum $\operatorname{IgG}<5 \mathrm{~g} / \mathrm{L}$ (excluding paraprotein)" (205).

Guidelines published in 2011 by the UK Department of Health (229) recommend that "Immunoglobulin replacement therapy is recommended in secondary antibody deficiency if the underlying cause of hypogammaglobulinaemia cannot be reversed or reversal is contraindicated, or is associated with B-cell malignancy where severe infections with encapsulated bacteria are persistent despite prophylactic antibiotic therapy (grade C recommendation, level III evidence)" (229).

The Criteria for Clinical Use of Immunoglobulin from the National Blood Authority in Australia provide a variety of recommendations for IgRT, including: "Prevention of recurrent bacterial infections due to hypogammaglobulinaemia associated with hematological malignancies or post haemopoietic stem cell transplant" (230), and "replacement therapy for recurrent or severe bacterial infections or disseminated enterovirus infection associated with hypogammaglobulinaemia caused by a recognized disease process or $B$ cell depletion therapy and/or immunosuppressant therapy" (231). Finally, in Canada, guidelines published in 2018 state that "Immunoglobulin replacement is recommended for preventing recurrent, severe infection due to hypogammaglobulinemia (excluding paraprotein) related to other diseases or medical therapy" (232). Specifically, secondary antibody deficiency is defined as "Hypogammaglobulinemia secondary to underlying disease or medical therapy (including HSCT) with all of the following: Serum IgG less than the lower limit of the reference range on two separate occasions AND at least one of the following: a) one invasive or life-threatening bacterial infection (e.g., pneumonia, meningitis, sepsis) in the previous year; b) recurrent, severe bacterial infections; c) Clinically active bronchiectasis confirmed by radiology or d) 


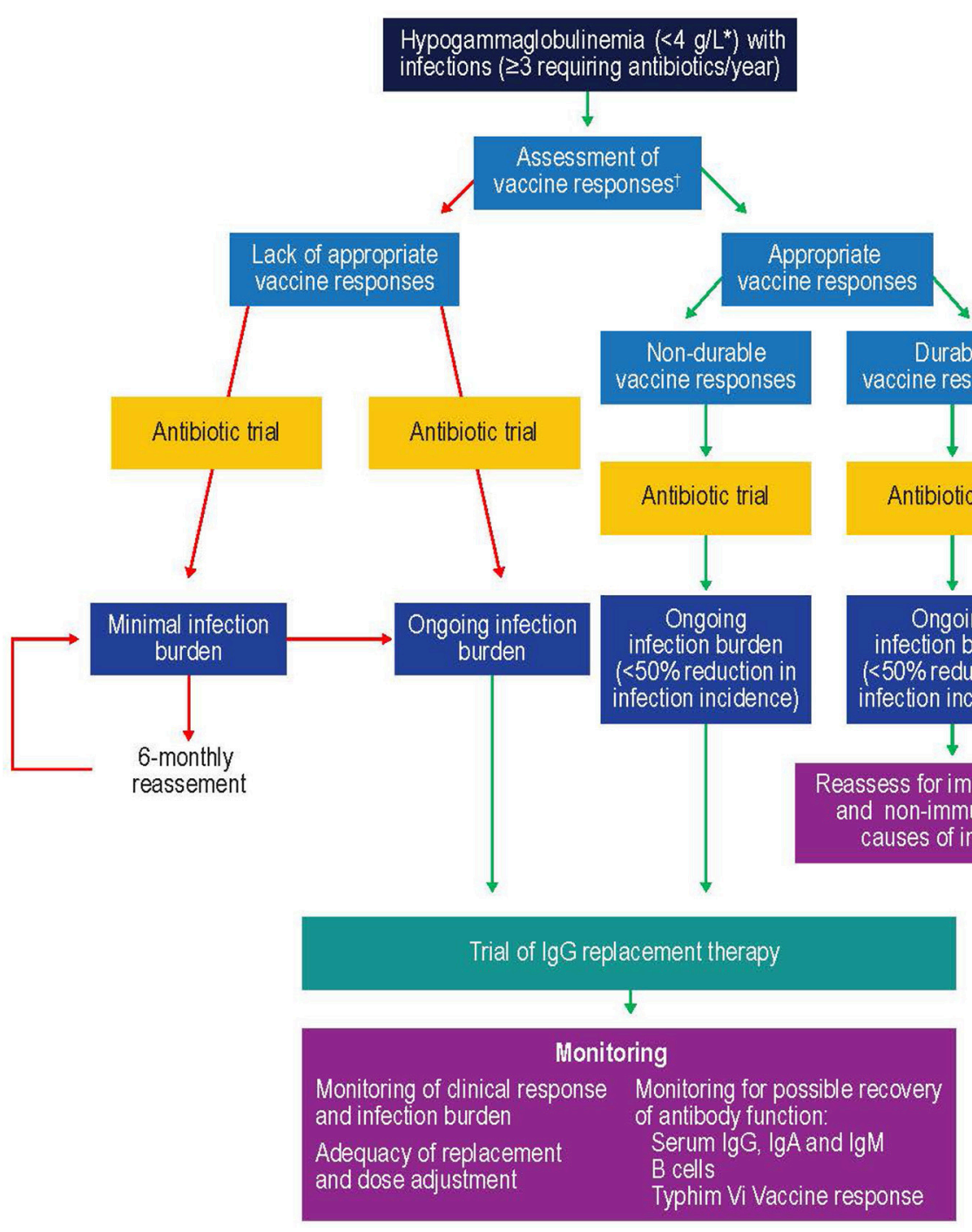

FIGURE 5 | Suggested protocol for the investigation, monitoring, and management of secondary antibody deficiency. Reproduced with the permission of the copyright holder John Wiley \& Sons Inc (5). *See (57, 58, 214); ${ }^{\dagger}$ Only > 6 month after solid organ transplant. CSMB, class-switched memory B cells; IgA, immunoglobulin A; IgG, immunoglobulin G; IgM, immunoglobulin M; SOT, solid organ transplant.

assessment by a physician specializing in immunodeficiency indicating a significant antibody defect that would benefit from immunoglobulin replacement" (232).

In the field of SOT, there are currently no published guidelines regarding the use of IgRT in patients with recurrent bacterial infections and hypogammaglobulinemia. In the updated International Consensus Guidelines on the management of CMV in SOT, published by the Transplantation Society International CMV Consensus Group, there is a recommendation that, when CMV disease is difficult to control, IgG testing is advisable (170). According to expert opinion, CMV-specific IgRT is recommended for prophylaxis of CMV disease in high risk $\mathrm{CMV}$ seronegative recipients in specific settings, such as thoracic, intestinal, and pediatric transplantation (170). The European Society of Clinical Microbiology and Infectious
Diseases guidelines recommend antiviral prophylaxis treatment for patients at high risk of CMV disease, such as lung and intestinal transplant recipients (233).

Overall, most guidelines are in support of considering IgRT initiation in selected patients with secondary antibody deficiency. In patients with risk factors (e.g., cardiovascular disease, diabetes, renal impairment, and thrombosis risk), a careful riskbenefit assessment should determine whether initiating IgRT is advisable. Also, the dose, route, and administration frequency should be optimized for each patient individually to maintain acceptable plasma IgG levels and a substantial reduction of infection rates (234). However, further clinical studies are required to improve and/or validate our current practice in prescribing IgG to patients with secondary antibody deficiency especially given the growth in newer therapies. It is also clear 
that individual assessment remains paramount, as diagnostic testing remains imperfect and not all patients will fit neatly into guidelines.

\section{FUTURE DIRECTIONS}

As the number and variety of immunosuppressive therapies increases, so will the incidence of secondary antibody deficiency (5). Accordingly, the EMA are currently in the process of updating their guidelines on the use of IVIG to specifically address secondary antibody deficiency, recommending its use for "secondary immunodeficiencies in patients who suffer from severe or recurrent bacterial infections, ineffective antibiotic treatment and either proven specific antibody failure (failure to mount at least a 2-fold rise in IgG antibody titer to pneumococcal polysaccharide and polypeptide antigen vaccines) or serum IgG level of $<4$ $g / L "$ (235). Their recommended dose is $0.2-0.4 \mathrm{~g} / \mathrm{kg}$ every 3 to 4 weeks. Indeed, there is also increasing evidence that SCIG offers an efficacious and efficient treatment option for secondary antibody deficiency (236).

It should be emphasized that currently, evidence regarding the newer agents is limited by study size, duration, and the number of disease settings, and longer-term prospective follow-up studies will be needed to clearly define the long term cumulative effect on antibody production and thus inform future guidelines.

In $\mathrm{PAD}$, there are screening and treatment guidelines and protocols in place to identify and treat hypogammaglobulinemia (237-239). However, even in these newer, updated guidelines, there remains a paucity of recommendations related to the diagnosis and screening for secondary antibody deficiency or those addressing the treatment of secondary antibody deficiency specifically. As discussed above, vaccine-specific antibody response is a key tool in the diagnosis of secondary antibody deficiency that will benefit from new assays to assess responses to polysaccharide vaccination, such as Typhim $\mathrm{Vi}$ (typhoid polysaccharide vaccine, Sanofi Pasteur, UK), which are being increasingly introduced $(240,241)$. It will also be important to harness pharmacogenetics in patient selection and risk stratification. Future guidelines will need to focus on these under-represented and rapidly growing patient populations to harmonize and optimize screening, diagnostic, monitoring, and management approaches.

\section{Avoiding the Consequences of Hypogammaglobulinemia}

Ongoing advances in testing, earlier screening, reducing diagnostic delay, and optimizing treatment regimens are all ways to reduce the burden of secondary antibody deficiency. Determining the concentration of the serum globulin fraction (calculated globulin), of which immunoglobulins are a major component, is a useful tool for identifying undiagnosed patients with secondary antibody deficiency $(242,243)$. However, given the variety of causes and settings in which secondary antibody deficiency may present, raising awareness of conditions, and treatments that increase the risk of secondary antibody deficiency is also vital (Figure 5).
The identification of biomarkers, such as those following heart transplantation (e.g., low anti-CD8 response to CMV, reduced complement components), will help to stratify patients by risk and improve recognition. In a wider context, clinical biomarkers that may assist in patient identification may include infection burden (particularly sinopulmonary infection), chronic sinusitis, chronic daily sputum production suggestive of bronchiectasis (5), or $\operatorname{IgG}$ level $(<4 \mathrm{~g} / \mathrm{L})$. With regard to infection burden, factors such as infection frequency, duration, severity, and site should be considered, along with rates of antibiotic (particularly intravenous) use and hospitalization. Alongside vaccine responses, it is advisable to consider other factors, such as neutropenia, significant renal impairment, multiple lines of treatments, and ongoing therapy requirement and timing of vaccination (e.g., in relation to HSCT). In addition, performing measurements of potential biomarkers at baseline will enable objective measurement of the outcome of subsequent interventions (5).

\section{CONCLUSIONS}

The prevalence and burden of secondary antibody deficiency are substantial and increasing. Secondary antibody deficiency occurs in the majority of patients with hematological malignancies, such as CLL and MM, either as a result of disease-related effects on the immune system or as a side effect of the treatment. Secondary antibody deficiency can also emerge in less well-known at-risk patient populations, such as patients undergoing SOT (due to post-transplantation immunosuppressive therapy) (6), patients with neurological conditions $(129,130)$ and patients with psychiatric conditions (70). With the growth in new and more effective improved therapies for malignancy and organ transplantation, the incidence of secondary antibody deficiency is likely to increase further, in particular when targeting different and multiple components of B cell development and survival (Figure 2). As the use of these newer, more effective immunosuppressive medications becomes more prevalent, the resultant increased survival in malignancy will be accompanied by a concomitant increase in the prevalence of secondary antibody deficiency. Given the diverse etiologies of secondary antibody deficiency, healthcare practitioners from a wide range of specialties will need to anticipate the possible immunological adverse effects of the new therapeutic agents targeting the immune system. Not surprisingly, secondary antibody deficiency is often missed despite recurrent infections, resulting in delayed diagnosis and intervention (168). Therefore, there is a real need for increased awareness, screening, and improved monitoring of patients at risk of developing secondary antibody deficiency to aid early identification of these patients to avoid infection-related morbidity and mortality.

Improved screening, such as by measuring calculated globulin, is an important goal in the quest for identifying secondary antibody deficiency as early as possible. In addition, improved risk stratification and the use of biomarkers to 
identify the patients most likely to require interventions, such as IgRT, within each patient population will be key. secondary antibody deficiency patients will be no less individual than PAD patients and should have the same access to treatments once antibody failure has been demonstrated. The limited evidence available in secondary antibody deficiency suggests that there are significant similarities in management approaches with those used for PAD. However, cohort and prospective studies in secondary antibody deficiency are needed to support decisions regarding patient selection and treatment with targeted vaccination, prophylactic antibiotics, or IgRT. These studies should also help to identify any distinctive clinical features that may differ depending on the etiology of secondary antibody deficiency (e.g., drug-induced vs. malignancy vs. specific disease

\section{REFERENCES}

1. Picard C, Al-Herz W, Bousfiha A, Casanova JL, Chatila T, Conley ME, et al. Primary immunodeficiency diseases: an update on the classification from the International Union of Immunological Societies Expert Committee for Primary Immunodeficiency 2015. J Clin Immunol. (2015) 35:696-726. doi: 10.1007/s10875-015-0201-1

2. Srivastava S, Wood P. Secondary antibody deficiency - causes and approach to diagnosis. Clin Med. (2016) 16:571-6. doi: 10.7861/clinmedicine.16-6-571

3. Boyle JM, Buckley RH. Population prevalence of diagnosed primary immunodeficiency diseases in the United States. J Clin Immunol. (2007) 27:497-502. doi: 10.1007/s10875-007-9103-1

4. Chinen J, Shearer WT. Secondary immunodeficiencies, including HIV infection. J Allergy Clin Immunol. (2010) 125(2 Suppl.):S195-203. doi: 10.1016/j.jaci.2009.08.040

5. Jolles S, Chapel H, Litzman J. When to initiate immunoglobulin replacement therapy (IGRT) in antibody deficiency: a practical approach. Clin Exp Immunol. (2017) 188:333-41. doi: 10.1111/cei.12915

6. Friman V, Winqvist O, Blimark C, Langerbeins P, Chapel H, Dhalla F. Secondary immunodeficiency in lymphoproliferative malignancies. Hematol Oncol. (2016) 34:121-32. doi: 10.1002/hon.2323

7. Kiessling P, Lledo-Garcia R, Watanabe S, Langdon G, Tran D, Bari M, et al. The FcRn inhibitor rozanolixizumab reduces human serum IgG concentration: a randomized phase 1 study. Sci Transl Med. (2017) 9: eaan1208. doi: 10.1126/scitranslmed.aan 1208

8. Ulrichts P, Guglietta A, Dreier T, van Bragt T, Hanssens V, Hofman E, et al. Neonatal Fc receptor antagonist efgartigimod safely and sustainably reduces IgGs in humans. J Clin Investig. (2018) 128:4372-86. doi: 10.1172/ JCI97911

9. Guptill JT, Juel VC, Massey JM, Anderson AC, Chopra M, Yi JS, et al. Effect of therapeutic plasma exchange on immunoglobulins in myasthenia gravis. Autoimmunity (2016) 49:472-9. doi: 10.1080/08916934.2016.1214823

10. Pohl MA, Lan S, Berl T, Lupus Nephritis Collaborative Study Group. PLasmapheresis does not increase the risk for infection in immunosuppressed patients with severe lupus nephritis. Ann Intern Med. (1991) 114:924-9. doi: 10.7326/0003-4819-114-11-924

11. Agostini C, Blau IW, Kimby E, Plesner T. Prophylactic immunoglobulin therapy in secondary immune deficiency - an expert opinion. Expert Rev Clin Immunol. (2016) 12:921-6. doi: 10.1080/1744666X.2016.1208085

12. ADIVO. Historical Audit Analysis (2017).

13. Dhalla F, Lucas M, Schuh A, Bhole M, Jain R, Patel SY, et al. Antibody deficiency secondary to chronic lymphocytic leukemia: should patients be treated with prophylactic replacement immunoglobulin? J Clin Immunol. (2014) 34:277-82. doi: 10.1007/s10875-014-9995-5

14. National Cancer Institute. Cancer Stat Facts: Myeloma. Available online at: https://seer.cancer.gov/statfacts/html/mulmy.html (Accessed January 15, 2019). vs. transplantation setting) and how to optimize management of this under-appreciated condition.

\section{AUTHOR CONTRIBUTIONS}

All authors listed have made a substantial, direct and intellectual contribution to the work, and approved it for publication.

\section{ACKNOWLEDGMENTS}

Editorial and graphical support was provided by Vibhuti Singh and Heather Shawcross, Fishawack Communications $\mathrm{GmbH}$, Basel, Switzerland, a member of the Fishawack Group of Companies, supported by CSL Behring.

15. National Cancer Institute. Cancer Stat Facts: LeumQ14kemia - Chronic Lymphocytic Leukemia.Available online at: https://seer.cancer.gov/statfacts/ html/clyl.html (Accessed January 15, 2019).

16. Byrd JC, O’Brien S, James DF. Ibrutinib in relapsed chronic lymphocytic leukemia. N Engl J Med. (2013) 369:1278-9. doi: 10.1056/NEJMoa1215637

17. Casulo C, Maragulia J, Zelenetz AD. Incidence of hypogammaglobulinemia in patients receiving rituximab and the use of intravenous immunoglobulin for recurrent infections. Clin Lymphoma Myeloma Leuk. (2013) 13:106-11. doi: 10.1016/j.clml.2012.11.011

18. Compagno N, Cinetto F, Semenzato G, Agostini C. Subcutaneous immunoglobulin in lymphoproliferative disorders and rituximabrelated secondary hypogammaglobulinemia: a single-center experience in 61 patients. Haematologica (2014) 99:1101-6. doi: 10.3324/haematol.2013.101261

19. Gunther G, Dreger B. Post-marketing observational study on $5 \%$ intravenous immunoglobulin therapy in patients with secondary immunodeficiency and recurrent serious bacterial infections. Microbiol Immunol. (2013) 57:527-35. doi: 10.1111/1348-0421.12060

20. Adivo Associates. Market Research: immunoglobulin Usage in SID (2016).

21. Seppänen M. Immunoglobulin G treatment of secondary immunodeficiencies in the era of novel therapies. Clin Exp Immunol. (2014) 178(Suppl. 1):10-3. doi: 10.1111/cei.12493

22. Tete SM, Bijl M, Sahota SS, Bos NA. Immune defects in the risk of infection and response to vaccination in monoclonal gammopathy of undetermined significance and multiple myeloma. Front Immunol. (2014) 5:257. doi: 10.3389/fimmu.2014.00257

23. Blimark C, Holmberg E, Mellqvist UH, Landgren O, Bjorkholm M, Hultcrantz M, et al. Multiple myeloma and infections: a population-based study on 9253 multiple myeloma patients. Haematologica (2015) 100:107-13. doi: 10.3324/haematol.2014.107714

24. Kay NE. Abnormal T-cell subpopulation function in CLL: excessive suppressor ( $\mathrm{T}$ gamma) and deficient helper ( $\mathrm{T} \mathrm{mu}$ ) activity with respect to B-cell proliferation. Blood (1981) 57:418-20.

25. Dighiero G. An attempt to explain disordered immunity and hypogammaglobulinemia in B-CLL. Nouv Rev Fr Hematol. (1988) 30:283-8.

26. Hamblin AD, Hamblin TJ. The immunodeficiency of chronic lymphocytic leukaemia. Br Med Bull. (2008) 87:49-62. doi: 10.1093/bmb/ldn034

27. Sampalo A, Navas G, Medina F, Segundo C, Camara C, Brieva JA. Chronic lymphocytic leukemia B cells inhibit spontaneous Ig production by autologous bone marrow cells: role of CD95-CD95L interaction. Blood (2000) 96:3168-74. Available online at: http://www.bloodjournal.org/ content/96/9/3168

28. Anaissie EJ, Kontoyiannis DP, O’Brien S, Kantarjian H, Robertson L, Lerner S, et al. INfections in patients with chronic lymphocytic leukemia treated with fludarabine. Ann Intern Med. (1998) 129:559-66. doi: 10.7326/0003-4819-129-7-19981001000010 
29. Nucci M, Anaissie E. Infections in patients with multiple myeloma in the era of high-dose therapy and novel agents. Clin Infect Dis. (2009) 49:1211-25. doi: $10.1086 / 605664$

30. Dall'Era M, Chakravarty E, Wallace D, Genovese M, Weisman M, Kavanaugh A, et al. Reduced B lymphocyte and immunoglobulin levels after atacicept treatment in patients with systemic lupus erythematosus: results of a multicenter, phase ib, double-blind, placebo-controlled, dose-escalating trial. Arthritis Rheum. (2007) 56:4142-50. doi: 10.1002/art.23047

31. Ansell SM, Witzig TE, Inwards DJ, Porrata LF, Ythier A, Ferrande L, et al. Phase I clinical study of atacicept in patients with relapsed and refractory B-cell non-Hodgkin's lymphoma. Clin Cancer Res. (2008) 14:1105-10. doi: 10.1158/1078-0432.CCR-07-4435

32. Tak PP, Thurlings RM, Rossier C, Nestorov I, Dimic A, Mircetic V, et al. Atacicept in patients with rheumatoid arthritis: results of a multicenter, phase Ib, double-blind, placebo-controlled, dose-escalating, single- and repeateddose study. Arthritis Rheum. (2008) 58:61-72. doi: 10.1002/art.23178

33. Pena-Rossi C, Nasonov E, Stanislav M, Yakusevich V, Ershova O, Lomareva $\mathrm{N}$, et al. An exploratory dose-escalating study investigating the safety, tolerability, pharmacokinetics and pharmacodynamics of intravenous atacicept in patients with systemic lupus erythematosus. Lupus (2009) 18:547-55. doi: 10.1177/0961203309102803

34. Rossi JF, Moreaux J, Hose D, Requirand G, Rose M, Rouillé V, et al. Atacicept in relapsed/refractory multiple myeloma or active Waldenström's macroglobulinemia: a phase I study. Br J Cancer (2009) 101:1051-8. doi: 10.1038/sj.bjc.6605241

35. Genovese MC, Kinnman N, de La Bourdonnaye G, Pena Rossi C, Tak PP. Atacicept in patients with rheumatoid arthritis and an inadequate response to tumor necrosis factor antagonist therapy: results of a phase II, randomized, placebo-controlled, dose-finding trial. Arthritis Rheum. (2011) 63:1793-803. doi: 10.1002/art.30373

36. van Vollenhoven RF, Kinnman N, Vincent E, Wax S, Bathon J. Atacicept in patients with rheumatoid arthritis and an inadequate response to methotrexate: results of a phase II, randomized, placebo-controlled trial. Arthritis Rheum. (2011) 63:1782-92. doi: 10.1002/art.30372

37. Isenberg D, Gordon C, Licu D, Copt S, Rossi CP, Wofsy D. Efficacy and safety of atacicept for prevention of flares in patients with moderate-to-severe systemic lupus erythematosus (SLE): 52-week data (APRIL-SLE randomised trial). Ann Rheum Dis. (2015) 74:2006-15. doi: 10.1136/annrheumdis-2013-205067

38. Stohl W, Schwarting A, Okada M, Scheinberg M, Doria A, Hammer $\mathrm{AE}$, et al. Efficacy and safety of subcutaneous belimumab in systemic lupus erythematosus: a fifty-two-week randomized, double-blind, placebo-controlled study. Arthritis Rheumatol. (2017) 69:1016-27. doi: 10.1002/art.40049

39. Nagel J, Saxne T, Geborek P, Bengtsson AA, Jacobsen S, Svaerke Joergensen $\mathrm{C}$, et al. Treatment with belimumab in systemic lupus erythematosus does not impair antibody response to 13 -valent pneumococcal conjugate vaccine. Lupus (2017) 26:1072-81. doi: 10.1177/0961203317695465

40. Furie R, Stohl W, Ginzler EM, Becker M, Mishra N, Chatham W, et al. Biologic activity and safety of belimumab, a neutralizing anti-Blymphocyte stimulator (BLyS) monoclonal antibody: a phase I trial in patients with systemic lupus erythematosus. Arthritis Res Ther. (2008) 10:R109. doi: 10.1186/ar2506

41. Wallace DJ. Thrombovascular events in systemic lupus erythematosus: comment on the article by Jung et al. Arthritis Rheum. (2010) 62:2824-5. doi: 10.1002/art.27621

42. Furie R, Petri M, Zamani O, Cervera R, Wallace DJ, Tegzová D, et al. A phase III, randomized, placebo-controlled study of belimumab, a monoclonal antibody that inhibits B lymphocyte stimulator, in patients with systemic lupus erythematosus. Arthritis Rheum. (2011) 63:3918-30. doi: 10.1002 /art.30613

43. Jacobi AM, Huang W, Wang T, Freimuth W, Sanz I, Furie R, et al. Effect of long-term belimumab treatment on B cells in systemic lupus erythematosus: extension of a phase II, double-blind, placebo-controlled, dose-ranging study. Arthritis Rheum. (2010) 62:201-10. doi: 10.1002/art.27189

44. Chatham WW, Wallace DJ, Stohl W, Latinis KM, Manzi S, McCune WJ, et al. Effect of belimumab on vaccine antigen antibodies to influenza, pneumococcal, and tetanus vaccines in patients with systemic lupus erythematosus in the BLISS-76 trial. J Rheumatol. (2012) 39:1632-40. doi: 10.3899/jrheum.111587

45. Merrill JT, Ginzler EM, Wallace DJ, McKay JD, Lisse JR, Aranow C, et al. Long-term safety profile of belimumab plus standard therapy in patients with systemic lupus erythematosus. Arthritis Rheum. (2012) 64:3364-73. doi: 10.1002/art.34564

46. van Vollenhoven RF, Petri MA, Cervera R, Roth DA, Ji BN, Kleoudis CS, et al. Belimumab in the treatment of systemic lupus erythematosus: high disease activity predictors of response. Ann Rheum Dis. (2012) 71:1343-9. doi: 10.1136/annrheumdis-2011-200937

47. Stohl W, Merrill JT, McKay JD, Lisse JR, Zhong ZJ, Freimuth WW, et al. Efficacy and safety of belimumab in patients with rheumatoid arthritis: a phase II, randomized, double-blind, placebo-controlled, dose-ranging Study. J Rheumatol. (2013) 40:579-89. doi: 10.3899/jrheum.120886

48. Ginzler EM, Wallace DJ, Merrill JT, Furie RA, Stohl W, Chatham WW, et al. Disease control and safety of belimumab plus standard therapy over 7 years in patients with systemic lupus erythematosus. J Rheumatol. (2014) 41:300-9. doi: 10.3899/jrheum.121368

49. Pontarini E, Fabris M, Quartuccio L, Cappeletti M, Calcaterra F, Roberto A, et al. Treatment with belimumab restores $\mathrm{B}$ cell subsets and their expression of B cell activating factor receptor in patients with primary Sjogren's syndrome. Rheumatology (2015) 54:1429-34. doi: 10.1093/rheumatology/ kev005

50. Seror R, Nocturne G, Lazure T, Hendel-Chavez H, Desmoulins F, Belkhir $\mathrm{R}$, et al. Low numbers of blood and salivary natural killer cells are associated with a better response to belimumab in primary Sjogren's syndrome: results of the BELISS study. Arthritis Res Ther. (2015) 17:241. doi: 10.1186/s13075-015-0750-y

51. Quartuccio L, Salvin S, Corazza L, Gandolfo S, Fabris M, De Vita S. Efficacy of belimumab and targeting of rheumatoid factor-positive B-cell expansion in Sjogren's syndrome: follow-up after the end of the phase II open-label BELISS study. Clin Exp Rheumatol. (2016) 34:311-4.

52. Chatham W, Chadha A, Fettiplace J, Kleoudis C, Bass D, Roth $\mathrm{D}$, et al. A randomized, open-label study to investigate the effect of belimumab on pneumococcal vaccination in patients with active, autoantibody-positive systemic lupus erythematosus. Lupus (2017) 26:148390. doi: 10.1177/0961203317703495

53. Knauf WU, Lissichkov T, Aldaoud A, Liberati A, Loscertales J, Herbrecht $\mathrm{R}$, et al. Phase III randomized study of bendamustine compared with chlorambucil in previously untreated patients with chronic lymphocytic leukemia. J Clin Oncol. (2009) 27:4378-84. doi: 10.1200/JCO.2008.2 0.8389

54. Gafter-Gvili A, Polliack A. Bendamustine associated immune suppression and infections during therapy of hematological malignancies. Leuk Lymphoma (2016) 57:512-9. doi: 10.3109/10428194.2015.1110748

55. Gafter-Gvili A, Ribakovsky E, Mizrahi N, Avigdor A, Aviv A, Vidal L, et al. Infections associated with bendamustine containing regimens in hematological patients: a retrospective multi-center study. Leuk Lymphoma (2016) 57:63-9. doi: 10.3109/10428194.2015.1046862

56. Topp MS, Kufer P, Gökbuget N, Goebeler M, Klinger M, Neumann S, et al. Targeted therapy with the T-cell-engaging antibody blinatumomab of chemotherapy-refractory minimal residual disease in B-lineage acute lymphoblastic leukemia patients results in high response rate and prolonged leukemia-free survival. J Clin Oncol. (2011) 29:2493-8. doi: 10.1200/JCO.2010.32.7270

57. Klinger M, Brandl C, Zugmaier G, Hijazi Y, Bargou RC, Topp MS, et al. Immunopharmacologic response of patients with B-lineage acute lymphoblastic leukemia to continuous infusion of $\mathrm{T}$ cell-engaging CD19/CD3-bispecific BiTE antibody blinatumomab. Blood (2012) 119:622633. doi: 10.1182/blood-2012-01-400515

58. Zugmaier G, Topp MS, Alekar S, Viardot A, Horst HA, Neumann $\mathrm{S}$, et al. Long-term follow-up of serum immunoglobulin levels in blinatumomab-treated patients with minimal residual disease-positive Bprecursor acute lymphoblastic leukemia. Blood Cancer J. (2014) 4:244. doi: 10.1038/bcj.2014.64

59. Topp MS, Gokbuget N, Stein AS, Zugmaier G, O’Brien S, Bargou RC, et al. Safety and activity of blinatumomab for adult patients with relapsed or refractory B-precursor acute lymphoblastic leukaemia: a 
multicentre, single-arm, phase 2 study. Lancet Oncol. (2015) 16:57-66. doi: 10.1016/S1470-2045(14)71170-2

60. Goebeler M-E, Knop S, Viardot A, Kufer P, Topp MS, Einsele H, et al. Bispecific T-Cell Engager (BiTE) antibody construct blinatumomab for the treatment of patients with relapsed/refractory non-hodgkin lymphoma: final results from a phase I study. J Clin Oncol. (2016) 34:1104-11. doi: $10.1200 /$ JCO.2014.59.1586

61. Zhu M, Wu B, Brandl C, Johnson J, Wolf A, Chow A, et al. Blinatumomab, a Bispecific T-cell Engager (BiTEß) for CD-19 targeted cancer immunotherapy: clinical pharmacology and its implications. Clin Pharmacokinet. (2016) 55:1271-88. doi: 10.1007/s40262-016-0405-4

62. Chanan-Khan A, Sonneveld P, Schuster MW, Stadtmauer EA, Facon T, Harousseau JL, et al. Analysis of herpes zoster events among bortezomibtreated patients in the phase III APEX study. JClin Oncol. (2008) 26:4784-90. doi: 10.1200/JCO.2007.14.9641

63. Yi YS, Chung JS, Song MK, Shin HJ, Seol YM, Choi YJ, et al. The risk factors for herpes zoster in bortezomib treatment in patients with multiple myeloma. Korean J Hematol. (2010) 45:188-92. doi: 10.5045/kih.2010.45.3.188

64. Alexander T, Sarfert R, Klotsche J, Kühl AA, Rubbert-Roth A, Lorenz H-M, et al. The proteasome inhibitior bortezomib depletes plasma cells and ameliorates clinical manifestations of refractory systemic lupus erythematosus. Ann Rheum Dis. (2015) 74:1474-8. doi: 10.1136/annrheumdis-2014-206016

65. Hoofnagle JH, Davis GL, Schafer DF, Peters M, Avigan MI, Pappas SC, et al. Randomized trial of chlorambucil for primary biliary cirrhosis. Gastroenterology (1986) 91:1327-34. doi: 10.1016/0016-5085(86)90183-6

66. Montserrat E, Villamor N, Urbano-Ispizua A, Ribera JM, Lozano M, VivesCorrons JL, et al. Treatment of early stage-B chronic lymphocytic leukemia with alpha-2b interferon after chlorambucil reduction of the tumoral mass. Ann Hematol. (1991) 63:15-9. doi: 10.1007/BF01714955

67. Robak T, Błonski JZ, Urbanska-Ryś H, Błasinska-Morawiec M, Skotnicki AB. 2-Chlorodeoxyadenosine (Cladribine) in the treatment of patients with chronic lymphocytic leukemia 55 years old and younger. Leukemia (1999) 13:518-23.

68. Davis JC, Austin H, Boumpas D, Fleisher TA, Yarboro C, Larson A, et al. A pilot study of 2-chloro-2'-deoxyadenosine in the treatment of systemic lupus erythematosus-associated glomerulonephritis. Arthritis Rheum. (2004) 41:335-43. doi: 10.1002/1529-0131(199802)41:2<335::AID-ART18>3.0.CO;2-O

69. Inwards DJ, Fishkin PAS, Hillman DW, Brown DW, Ansell SM, Kurtin $\mathrm{PJ}$, et al. Long-term results of the treatment of patients with mantle cell lymphoma with cladribine (2-CDA) alone (95-80-53) or 2-CDA and rituximab (N0189) in the North Central Cancer Treatment Group. Cancer (2008) 113:108-16. doi: 10.1002/cncr.23537

70. Ponsford M, Castle D, Tahir T, Robinson R, Wade W, Steven R, et al. Clozapine is associated with secondary antibody deficiency. $\mathrm{Br} J$ Psychiatry (2018):1-7. doi: 10.1192/bjp.2018.152. [Epub ahead of print].

71. Hinze-Selch D, Becker EW, Stein GM, Berg PA, Mullington J, Holsboer F, et al. Effects of clozapine on in vitro immune parameters: a longitudinal study in clozapine-treated schizophrenic patients. Neuropsychopharmacology (1998) 19:114-22. doi: 10.1016/S0893-133X(98)00006-2

72. Lozano R, Marin R, Santacruz MJ, Pascual A. Effect of clozapine on immunoglobulin M plasma levels. Ther Adv Psychopharmacol. (2016) 6:5860. doi: 10.1177/2045125315591925

73. Wirsum C, Glaser C, Gutenberger S, Keller B, Unger S, Voll RE, et al. Secondary antibody deficiency in glucocorticoid therapy clearly differs from primary antibody deficiency. J Clin Immunol. (2016) 36:406-12. doi: 10.1007/s10875-016-0264-7

74. Kubiet MA, Gonzalez-Rothi RJ, Cottey R, Bender BS. Serum antibody response to influenza vaccine in pulmonary patients receiving corticosteroids. CHEST (1996) 110:367-70. doi: 10.1378/chest.110.2.367

75. Teh BW, Harrison SJ, Worth LJ, Spelman T, Thursky KA, Slavin MA. Risks, severity and timing of infections in patients with multiple myeloma: a longitudinal cohort study in the era of immunomodulatory drug therapy. Br J Haematol. (2015) 171:100-8. doi: 10.1111/bjh.13532

76. Krejcik J, Casneuf T, Nijhof IS, Verbist B, Bald J, Plesner T, et al. Daratumumab depletes CD38+ immune regulatory cells, promotes T-cell expansion, and skews T-cell repertoire in multiple myeloma. Blood (2016) 128:384-94. doi: 10.1182/blood-2015-12-687749

77. Johnsrud JJ, Susanibar S, Jo-Kamimoto J, Johnsrud AJ, Kothari A, Burgess $\mathrm{MJ}$, et al. Infection risk associated with daratumumab. Open Forum Infect Dis. (2017) 4(Suppl. 1):S702-S3. doi: 10.1093/ofid/ofx163.1884

78. Gottenberg JE, Dörner T, Bootsma H, Devauchelle-Pensec V, Bowman SJ, Mariette X, et al. Efficacy of Epratuzumab, an Anti-CD22 monoclonal IgG antibody, in systemic lupus erythematosus patients with associated Sjögren's Syndrome: post hoc analyses from the EMBODY trials. Arthritis Rheumatol. (2018) 70:763-73. doi: 10.1002/art.40425

79. Leonard JP, Coleman M, Ketas JC, Chadburn A, Furman R, Schuster MW, et al. Epratuzumab, a humanized anti-CD22 antibody, in aggressive non-Hodgkin's lymphoma. Phase I/II Clin Trial Results (2004) 10:5327-34. doi: 10.1158/1078-0432.CCR-04-0294

80. Steinfeld SD, Tant L, Burmester GR, Teoh NKW, Wegener WA, Goldenberg $\mathrm{DM}$, et al. Epratuzumab (humanised anti-CD22 antibody) in primary Sjögren's syndrome: an open-label phase I/II study. Arthritis Res Ther. (2006) 8:R129. doi: 10.1186/ar2018

81. Dörner T, Kaufmann J, Wegener WA, Teoh N, Goldenberg DM, Burmester GR. Initial clinical trial of epratuzumab (humanized anti-CD22 antibody) for immunotherapy of systemic lupus erythematosus. Arthritis Res. Ther. (2006) 8:R74. doi: $10.1186 /$ ar1942

82. Wallace DJ, Kalunian K, Petri MA, Strand V, Houssiau FA, Pike M, et al. Efficacy and safety of epratuzumab in patients with moderate/severe active systemic lupus erythematosus: results from EMBLEM, a phase IIb, randomised, double-blind, placebo-controlled, multicentre study. Ann Rheum Dis. (2014) 73:183-90. doi: 10.1136/annrheumdis-2012-202760

83. Tsuru T, Tanaka Y, Kishimoto M, Saito K, Yoshizawa S, Takasaki Y, et al. Safety, pharmacokinetics, and pharmacodynamics of epratuzumab in Japanese patients with moderate-to-severe systemic lupus erythematosus: results from a phase 1/2 randomized study. Modern Rheumatol. (2016) 26:87-93. doi: 10.3109/14397595.2015.1079292

84. Clowse MEB, Wallace DJ, Furie RA, Petri MA, Pike MC, Leszczynski P, et al. Efficacy and safety of epratuzumab in moderately to severely active systemic lupus erythematosus: results from two phase III randomized, double-blind, placebo-controlled trials. Arthritis Rheumatol. (2017) 69:36275. doi: 10.1002/art.39856

85. Perkins ND. The diverse and complex roles of NF-kappaB subunits in cancer. Nat Rev Cancer (2012) 12:121-32. doi: 10.1038/nrc3204

86. Advani RH, Buggy JJ, Sharman JP, Smith SM, Boyd TE, Grant B, et al. Bruton tyrosine kinase inhibitor ibrutinib (PCI-32765) has significant activity in patients with relapsed/refractory B-cell malignancies. J Clin Oncol. (2013) 31:88-94. doi: 10.1200/JCO.2012.42.7906

87. Byrd JC, Brown JR, O’Brien S, Barrientos JC, Kay NE, Reddy NM, et al. Ibrutinib versus ofatumumab in previously treated chronic lymphoid leukemia. N Engl J Med. (2014) 371:213-23. doi: 10.1056/NEJMoa1400376

88. O’Brien S, Furman RR, Coutre SE, Sharman JP, Burger JA, Blum KA, et al. Ibrutinib as initial therapy for elderly patients with chronic lymphocytic leukaemia or small lymphocytic lymphoma: an openlabel, multicentre, phase $1 \mathrm{~b} / 2$ trial. Lancet Oncol. (2014) 15:48-58. doi: 10.1016/S1470-2045(13)70513-8

89. Sun C, Tian X, Lee YS, Gunti S, Lipsky A, Herman SE, et al. Partial reconstitution of humoral immunity and fewer infections in patients with chronic lymphocytic leukemia treated with ibrutinib. Blood (2015) 126:22139. doi: 10.1182/blood-2015-04-639203

90. Sun C, Gao J, Couzens L, et al. Seasonal influenza vaccination in patients with chronic lymphocytic leukemia treated with ibrutinib. JAMA Oncol. (2016) 2:1656-7. doi: 10.1001/jamaoncol.2016.2437

91. UK CLL Forum. Ibrutinib for relapsed/refractory chronic lymphocytic leukemia: a UK and Ireland analysis of outcomes in 315 patients. Haematologica (2016) 101:1563-72. doi: 10.3324/haematol.2016.147900

92. Lampson BL, Kasar SN, Matos TR, Morgan EA, Rassenti L, Davids MS, et al. Idelalisib given front-line for treatment of chronic lymphocytic leukemia causes frequent immune-mediated hepatotoxicity. Blood (2016) 128:195203. doi: 10.1182/blood-2016-03-707133

93. Brown JR, Byrd JC, Coutre SE, Benson DM, Flinn IW, Wagner-Johnston $\mathrm{ND}$, et al. Idelalisib, an inhibitor of phosphatidylinositol 3-kinase p1108, for 
relapsed/refractory chronic lymphocytic leukemia. Blood (2014) 123:3390-7. doi: 10.1182/blood-2013-11-535047

94. Flinn IW, Kahl BS, Leonard JP, Furman RR, Brown JR, Byrd JC, et al. Idelalisib, a selective inhibitor of phosphatidylinositol 3kinase-delta, as therapy for previously treated indolent non-Hodgkin lymphoma. Blood (2014) 123:3406-13. doi: 10.1182/blood-2013-11-5 38546

95. Gopal AK, Kahl BS, de Vos S, Wagner-Johnston ND, Schuster SJ, Jurczak WJ, et al. PI3K $\delta$ inhibition by idelalisib in patients with relapsed indolent lymphoma. N Engl J Med. (2014) 370:1008-18. doi: 10.1056/NEJMoa1314583

96. Agius MA, Klodowska-Duda G, Maciejowski M, Potemkowski A, Li J, Patra K, et al. Safety and tolerability of inebilizumab (MEDI-551), an anti-CD19 monoclonal antibody, in patients with relapsing forms of multiple sclerosis: results from a phase 1 randomised, placebocontrolled, escalating intravenous and subcutaneous dose study. Mult Scler J. (2017):1352458517740641. doi: 10.1177/1352458517740641. [Epub ahead of print].

97. Schiopu E, Chatterjee S, Hsu V, Flor A, Cimbora D, Patra K, et al. Safety and tolerability of an anti-CD19 monoclonal antibody, MEDI551, in subjects with systemic sclerosis: a phase I, randomized, placebocontrolled, escalating single-dose study. Arthritis Res Ther. (2016) 18:131. doi: 10.1186/s13075-016-1021-2

98. Smith KGC, Isbel NM, Catton MG, Leydon JA, Becker GJ, Walker RG. Suppression of the humoral immune response by mycophenolate mofetil. Nephrol Dialys Transplant. (1998) 13:160-4. doi: 10.1093/ndt/13.1.160

99. Munoz MA, Andres A, Gallego R, Morales E, Morales JM, Aguado JM, et al. Mycophenolate mofetil immunosuppressive therapies increase the incidence of cytomegalovirus infection in renal transplantation. Transplant Proc. (2002) 34:97. doi: 10.1016/S0041-1345(01)02683-5

100. Yip NH, Lederer DJ, Kawut SM, Wilt JS, D'Ovidio F, Wang Y, et al. Immunoglobulin $\mathrm{G}$ levels before and after lung transplantation. Am J Respir Crit Care Med. (2006) 173:917-21. doi: 10.1164/rccm.200510-1609OC

101. Fassbinder T, Saunders U, Mickholz E, Jung E, Becker H, Schluter $B$, et al. Differential effects of cyclophosphamide and mycophenolate mofetil on cellular and serological parameters in patients with systemic lupus erythematosus. Arthritis Res Ther. (2015) 17:92. doi: 10.1186/s13075-015-0603-8

102. Subedi A, Magder LS, Petri M. Effect of mycophenolate mofetil on the white blood cell count and the frequency of infection in systemic lupus erythematosus. Rheumatol Int. (2015) 35:1687-92. doi: 10.1007/s00296-015-3265-6

103. Genovese MC, Kaine JL, Lowenstein MB, Del Giudice J, Baldassare A, Schechtman J, et al. Ocrelizumab, a humanized anti-CD20 monoclonal antibody, in the treatment of patients with rheumatoid arthritis: a phase I/II randomized, blinded, placebo-controlled, dose-ranging study. Arthritis Rheum. (2008) 58:2652-61. doi: 10.1002/art.23732

104. Kappos L, Li D, Calabresi PA, O'Connor P, Bar-Or A, Barkhof F, et al. Ocrelizumab in relapsing-remitting multiple sclerosis: a phase 2, randomised, placebo-controlled, multicentre trial. Lancet (2011) 378:177987. doi: 10.1016/S0140-6736(11)61649-8

105. Harigai M, Tanaka Y, Maisawa S. Safety and efficacy of various dosages of ocrelizumab in Japanese patients with rheumatoid arthritis with an inadequate response to methotrexate therapy: a Placebo-Controlled Double-Blind Parallel-group Study. J Rheumatol. (2012) 39:486-95. doi: 10.3899/jrheum.110994

106. Stohl W, Gomez-Reino J, Olech E, Dudler J, Fleischmann RM, Zerbini CAF, et al. Safety and efficacy of ocrelizumab in combination with methotrexate in MTX-naive subjects with rheumatoid arthritis: the phase III FILM trial. Ann Rheum Dis. (2012) 71:1289-96. doi: 10.1136/annrheumdis-2011-200706

107. Tak PP, Mease PJ, Genovese MC, Kremer J, Haraoui B, Tanaka Y, et al. Safety and efficacy of ocrelizumab in patients with rheumatoid arthritis and an inadequate response to at least one tumor necrosis factor inhibitor: results of a forty-eight-week randomized, double-blind, placebocontrolled, parallel-group phase III trial. Arthritis Rheum. (2012) 64:360-70. doi: 10.1002/art.33353

108. Mysler EF, Spindler AJ, Guzman R, Bijl M, Jayne D, Furie RA, et al. Efficacy and safety of ocrelizumab in active proliferative lupus nephritis: results from a randomized, double-blind, phase III study. Arthritis Rheum. (2013) 65:2368-79. doi: 10.1002/art.38037

109. Hauser SL, Bar-Or A, Comi G, Giovannoni G, Hartung HP, Hemmer B, et al. Ocrelizumab versus Interferon Beta-1a in Relapsing Multiple Sclerosis. N Engl J Med. (2017) 376:221-34. doi: 10.1056/NEJMoa1601277

110. Montalban X, Hauser SL, Kappos L, Arnold DL, Bar-Or A, Comi G, et al. Ocrelizumab versus placebo in primary progressive multiple sclerosis. $N$ Engl J Med. (2017) 376:209-20. doi: 10.1056/NEJMoa1606468

111. Lim SH, Zhang Y, Wang Z, Esler WV, Beggs D, Pruitt B, et al. Maintenance rituximab after autologous stem cell transplant for high-risk B-cell lymphoma induces prolonged and severe hypogammaglobulinemia. Bone Marrow Transplant. (2004) 35:207-8. doi: 10.1038/sj.bmt. 1704742

112. Bingham III CO, Looney RJ, Deodhar A, Halsey N, Greenwald M, Codding $\mathrm{C}$, et al. Immunization responses in rheumatoid arthritis patients treated with rituximab: results from a controlled clinical trial. Arthritis Rheum. (2009) 62:64-74. doi: 10.1002/art.25034

113. Tobinai $\mathrm{K}$, Igarashi $\mathrm{T}$, Itoh $\mathrm{K}$, Kurosawa $\mathrm{M}$, Nagai $\mathrm{H}$, Hiraoka $\mathrm{A}$, et al. Rituximab monotherapy with eight weekly infusions for relapsed or refractory patients with indolent B cell non-Hodgkin lymphoma mostly pretreated with rituximab: a multicenter phase II study. Cancer Sci. (2011) 102:1698-705. doi: 10.1111/j.1349-7006.2011.02001.x

114. Nazi I, Kelton JG, Larché M, Snider DP, Heddle NM, Crowther $\mathrm{MA}$, et al. The effect of rituximab on vaccine responses in patients with immune thrombocytopenia. Blood (2013) 122:1946-53. doi: 10.1182/blood-2013-04-494096

115. Besada E, Koldingsnes W, Nossent JC. Serum immunoglobulin levels and risk factors for hypogammaglobulinaemia during long-term maintenance therapy with rituximab in patients with granulomatosis with polyangiitis. Rheumatology (2014) 53:1818-24. doi: 10.1093/rheumatology/keu194

116. Makatsori M, Kiani-Alikhan S, Manson AL, Verma N, Leandro M, Gurugama NP, et al. Hypogammaglobulinaemia after rituximab treatment-incidence and outcomes. QJM Int J Med. (2014) 107:821-8. doi: 10.1093/qjmed/hcu094

117. Aguiar R, Araújo C, Martins-Coelho G, Isenberg D. Use of rituximab in systemic lupus erythematosus: a single center experience over 14 years. Arthritis Care Res. (2016) 69:257-62. doi: 10.1002/acr.22921

118. Shah S, Jaggi K, Greenberg K, Geetha D. Immunoglobulin levels and infection risk with rituximab induction for anti-neutrophil cytoplasmic antibody-associated vasculitis. Clin Kidney J. (2017) 10:470-4. doi: $10.1093 / \mathrm{ckj} / \mathrm{sfx} 014$

119. Levy J, Barnett EV, MacDonald NS, Klinenberg JR, Pearson CM. The effect of azathioprine on gammaglobulin synthesis in man. J Clin Investig. (1972) 51:2233-8. doi: 10.1172/JCI107031

120. Jeurissen MEC, Th. Boerbooms AM, Van De Putte LBA, Doesburg WH, Mulder J, Rasker JJ, et al. Methotrexate versus azathioprine in the treatment of rheumatoid arthritis. A forty-eight-week randomized, double-blind trial. Arthritis Rheum. (1991) 34:961-72. doi: 10.1002/art.1780340805

121. Keven K, Sahin M, Kutlay S, Sengul S, Erturk S, Ersoz S, et al. Immunoglobulin deficiency in kidney allograft recipients: comparative effects of mycophenolate mofetil and azathioprine. Transplant Infect Dis. (2003) 5:181-6. doi: 10.1111/j.1399-3062.2003.00035.x

122. Dotan I, Werner L, Vigodman S, Agarwal S, Pfeffer J, Horowitz N, et al. Normal response to vaccines in inflammatory bowel disease patients treated with thiopurines. Inflamm Bowel Dis. (2012) 18:261-8. doi: 10.1002/ibd.21688

123. Dhalla F, Misbah SA. Secondary antibody deficiencies. Curr Opin Allergy Clin Immunol. (2015) 15:505-13. doi: 10.1097/ACI.0000000000000215

124. Florescu DF, Kalil AC, Qiu F, Schmidt CM, Sandkovsky U. What is the impact of hypogammaglobulinemia on the rate of infections and survival in solid organ transplantation? A meta-analysis. Am J Transplant. (2013) 13:2601-10. doi: 10.1111/ajt.12401

125. Sarmiento E, Jaramillo M, Calahorra L, Fernandez-Yanez J, Gomez-Sanchez M, Crespo-Leiro MG, et al. Evaluation of humoral immunity profiles to identify heart recipients at risk for development of severe infections: a multicenter prospective study. J Heart Lung Transplant. (2017) 36:529-39. doi: 10.1016/j.healun.2016.10.004 
126. Sarmiento E, Rodriguez-Molina J, Munoz P, Fernandez-Yanez J, Palomo J, Fogueda M, et al. Decreased levels of serum immunoglobulins as a risk factor for infection after heart transplantation. Transplant Proc. (2005) 37:4046-9. doi: 10.1016/j.transproceed.2005.09.153

127. Cortazar FB, Pendergraft WF, Wenger J, Owens CT, Laliberte K, Niles JL. The effect of continuous $\mathrm{B}$ cell depletion with rituximab on pathogenic autoantibodies and total IgG levels in ANCA vasculitis. Arthritis Rheumatol. (2017) 69:1045-53. doi: 10.1002/art.40032

128. van Vollenhoven RF, Emery P, Bingham CO, Keystone EC, Fleischmann RM, Furst DE, et al. Long-term safety of rituximab in rheumatoid arthritis: 9.5-year follow-up of the global clinical trial programme with a focus on adverse events of interest in RA patients. Ann Rheum Dis. (2013) 72:1496-502. doi: 10.1136/annrheumdis-2012201956

129. Tallantyre EC, Robertson NP, Jolles S. Secondary antibody deficiency in neurology. Curr Opin Allergy Clin Immunol. (2018) 18:481-8. doi: 10.1097/ACI.0000000000000485

130. Tallantyre EC, Whittam DH, Jolles S, Paling D, Constantinesecu C, Robertson NP, et al. Secondary antibody deficiency: a complication of anti-CD20 therapy for neuroinflammation. J Neurol. (2018) 265:1115-22. doi: 10.1007/s00415-018-8812-0

131. Long M, Beckwith K, Do P, Mundy BL, Gordon A, Lehman AM, et al. Ibrutinib treatment improves $\mathrm{T}$ cell number and function in CLL patients. J Clin Invest. (2017) 127:3052-64. doi: 10.1172/JCI89756

132. Parmar S, Patel K, Pinilla-Ibarz J. Ibrutinib (imbruvica): a novel targeted therapy for chronic lymphocytic leukemia. P T. (2014) 39:483-519.

133. Golay J, D’Amico A, Borleri G, Bonzi M, Valgardsdottir R, Alzani R, et al. A novel method using blinatumomab for efficient, clinical-grade expansion of polyclonal T cells for adoptive immunotherapy. J Immunol. (2014) 193:473947. doi: 10.4049/jimmunol.1401550

134. Kalaycio ME, George Negrea O, Allen SL, Rai KR, Abbasi RM, Horne $\mathrm{H}$, et al. Subcutaneous injections of low doses of humanized antiCD20 veltuzumab: a phase I study in chronic lymphocytic leukemia*. Leuk Lymphoma (2016) 57:803-11. doi: 10.3109/10428194.2015.10 85531

135. Babiker HM, Glode AE, Cooke LS, Mahadevan D. Ublituximab for the treatment of $\mathrm{CD} 20$ positive B-cell malignancies. Expert Opin Investig Drugs (2018) 27:407-12. doi: 10.1080/13543784.2018.14 59560

136. Said R, Tsimberidou AM. Obinutuzumab for the treatment of chronic lymphocytic leukemia and other B-cell lymphoproliferative disorders. Expert Opin Biol Ther. (2017) 17:1463-70. doi: 10.1080/14712598.2017.13 77178

137. Masoud S, McAdoo SP, Bedi R, Cairns TD, Lightstone L. Ofatumumab for $\mathrm{B}$ cell depletion in patients with systemic lupus erythematosus who are allergic to rituximab. Rheumatology (2018) 57:1156-61. doi: 10.1093/rheumatology/key042

138. van de Donk NWCJ. Immunomodulatory effects of CD38-targeting antibodies. Immunol Lett. (2018) 199:16-22. doi: 10.1016/j.imlet.2018.04.005

139. Geh D, Gordon C. Epratuzumab for the treatment of systemic lupus erythematosus. Expert Rev Clin Immunol. (2018) 14:245-58. doi: 10.1080/1744666X.2018.1450141

140. Martin P, Furman RR, Rutherford S, Ruan J, Ely S, Greenberg J, et al. Phase I study of the anti-CD74 monoclonal antibody milatuzumab (hLL1) in patients with previously treated B-cell lymphomas. Leuk Lymphoma (2015) 56:3065-70. doi: 10.3109/10428194.2015.10 28052

141. Syed YY. Ocrelizumab: a review in multiple sclerosis. CNS Drugs (2018) 32:883-90. doi: 10.1007/s40263-018-0568-7

142. Jain P, Kantarjian H, Alattar ML, Jabbour E, Sasaki K, Gonzalez GN, et al. Analysis of long term responses and their impact on outcomes in patients with chronic phase CML treated with four different TKI modalities analysis of 5 prospective clinical trials. Lancet Haematol. (2015) 2:e118-28. doi: 10.1016/S2352-3026(15)00021-6

143. Ursini F, Russo E, De Giorgio R, De Sarro G, D’Angelo S. Current treatment options for psoriatic arthritis: spotlight on abatacept. Ther Clin Risk Manag. (2018) 14:1053-9. doi: 10.2147/TCRM.S1 48586
144. Pellom ST, Dudimah DF, Thounaojam MC, Sayers TJ, Shanker A. Modulatory effects of bortezomib on host immune cell functions. Immunotherapy (2015) 7:1011-22. doi: 10.2217/imt.15.66

145. Witcher J, Fleischmann R, Chindalore VL, Hansen RJ, Hu L, Radtke D, et al. Pharmacokinetics and safety of single doses of tabalumab in subjects with rheumatoid arthritis or systemic lupus erythematosus. Br J Clin Pharmacol. (2016) 81:908-17. doi: 10.1111/bcp.12860

146. Cogollo E, Silva MA, Isenberg D. Profile of atacicept and its potential in the treatment of systemic lupus erythematosus. Drug Design Dev Ther. (2015) 9:1331-9. doi: 10.2147/DDDT.S71276

147. Sanchez L, Wang Y, Siegel DS, Wang ML. Daratumumab: a first-in-class CD38 monoclonal antibody for the treatment of multiple myeloma. $J$ Hematol Oncol. (2016) 9:51. doi: 10.1186/s13045-016-0283-0

148. Martin T, Baz R, Benson DM, Lendvai N, Wolf J, Munster P, et al. A phase $1 \mathrm{~b}$ study of isatuximab plus lenalidomide and dexamethasone for relapsed/refractory multiple myeloma. Blood (2017) 129:3294-303. doi: 10.1182/blood-2016-09-740787

149. Mikulska M, Lanini S, Gudiol C, Drgona L, Ippolito G, Fernández-Ruiz $\mathrm{M}$, et al. ESCMID Study Group for Infections in Compromised Hosts (ESGICH) Consensus Document on the safety of targeted and biological therapies: an infectious diseases perspective (Agents targeting lymphoid cells surface antigens [I]: CD19, CD20 and CD52). Clin Microbiol Infect. (2018) 24:S71-82. doi: 10.1016/j.cmi.2018.02.003

150. Emery P, Rigby W, Tak PP, Dörner T, Olech E, Martin C, et al. Safety with ocrelizumab in rheumatoid arthritis: results from the ocrelizumab phase III program. PLoS ONE (2014) 9:e87379. doi: 10.1371/journal.pone.0087379

151. Drgona L, Gudiol C, Lanini S, Salzberger B, Ippolito G, Mikulska M. ESCMID Study Group for Infections in Compromised Hosts (ESGICH) Consensus Document on the safety of targeted and biological therapies: an infectious diseases perspective (Agents targeting lymphoid or myeloid cells surface antigens [II]: CD22, CD30, CD33, CD38, CD40, SLAMF-7 and CCR4). Clin Microbiol Infect. (2018) 24:S83-94. doi: 10.1016/j.cmi.2018.03.022

152. Gordon C, Wofsy D, Wax S, Li Y, Pena Rossi C, Isenberg D. Post hoc Analysis of the Phase II/III APRIL-SLE study: association between response to atacicept and serum biomarkers including BLyS and APRIL. Arthritis Rheumatol. (2016) 69:122-30. doi: 10.1002/art.39809

153. Merrill JT, Wallace DJ, Wax S, Kao A, Fraser PA, Chang P, et al. Efficacy and safety of atacicept in patients with systemic lupus erythematosus. Arthritis Rheumatol. (2017) 70:266-76. doi: 10.1002/art.40360

154. van Vollenhoven RF, Wax S, Li Y, Tak PP. Safety and efficacy of atacicept in combination with rituximab for reducing the signs and symptoms of rheumatoid arthritis: a phase II, randomized, double-blind, placebo-controlled pilot trial. Arthritis Rheumatol. (2015) 67:2828-36. doi: 10.1002/art.39262

155. Maus MV, Grupp SA, Porter DL, June CH. Antibody-modified T cells: CARs take the front seat for hematologic malignancies. Blood (2014) 123:2625-35. doi: 10.1182/blood-2013-11-492231

156. Enblad G, Karlsson H, Gammelgard G, Wenthe J, Lovgren T, Amini RM, et al. A phase I/IIa trial using CD19-targeted third-generation CAR T cells for lymphoma and leukemia. Clin Cancer Res. (2018) 24:6185-94. doi: 10.1158/1078-0432.CCR-18-0426

157. Ramos CA, Rouce R, Robertson CS, Reyna A, Narala N, Vyas G, et al. In vivo fate and activity of second- versus third-generation CD19-specific CART cells in B cell non-Hodgkin's lymphomas. Mol Ther. (2018) 26:2727-37. doi: 10.1016/j.ymthe.2018.09.009

158. Reusch U, Duell J, Ellwanger K, Herbrecht C, Knackmuss SH, Fucek I, et al. A tetravalent bispecific TandAb (CD19/CD3), AFM11, efficiently recruits T cells for the potent lysis of CD19(+) tumor cells. MAbs (2015) 7:584-604. doi: 10.1080/19420862.2015.1029216

159. Roopenian DC, Akilesh S. FcRn: the neonatal Fc receptor comes of age. Nat Rev Immunol. (2007) 7:715-25. doi: 10.1038/nri2155

160. Organdonor.gov. Organ Donation Statistics (2016). Available online at: https://www.organdonor.gov/statistics-stories/statistics.html (Accessed January 15, 2019).

161. Reske A, Reske A, Metze M. Complications of immunosuppressive agents therapy in transplant patients. Minerva Anestesiol. (2015) 81:1244-61. doi: 10.1016/j.rcl.2015.09.009 
162. Yamani MH, Avery R, Mawhorter S, Young JB, McNeill A, Cook DJ, et al. Hypogammaglobulinemia after heart transplantation: impact of preemptive use of immunoglobulin replacement (CytoGam) on infection and rejection outcomes. Transpl Infect Dis. (2001) 3(Suppl. 2):40-3. doi: 10.1034/j.1399-3062.2001.00008.x

163. ISHLT International Registry for Heart and Lung Transplantation. Heart/Lung Registries (2017) Available online at: https://ishltregistries.org/ registries/slides.asp?year=2017 (Accessed January 15, 2019).

164. Compagno N, Malipiero G, Cinetto F, Agostini C. Immunoglobulin replacement therapy in secondary hypogammaglobulinemia. Front Immunol. (2014) 5:626. doi: 10.3389/fimmu.2014.00626

165. Sarmiento E, Rodriguez-Hernandez C, Rodriguez-Molina J, FernandezYanez J, Palomo J, Anguita J, et al. Impaired anti-pneumococcal polysaccharide antibody production and invasive pneumococcal infection following heart transplantation. Int Immunopharmacol. (2006) 6:2027-30. doi: 10.1016/j.intimp.2006.09.011

166. Christou EAA, Giardino G, Worth A, Ladomenou F. Risk factors predisposing to the development of hypogammaglobulinemia and infections post-Rituximab. Int Rev Immunol. (2017) 36:352-9. doi: 10.1080/08830185.2017.1346092

167. Cohen M, Romero G, Bas J, Ticchioni M, Rosenthal M, Lacroix $\mathrm{R}$, et al. Monitoring CD27+ memory B-cells in neuromyelitis optica spectrum disorders patients treated with rituximab: Results from a bicentric study. J Neurol Sci. (2017) 373:335-8. doi: 10.1016/j.jns.2017. 01.025

168. Duraisingham SS, Buckland MS, Grigoriadou S, Longhurst HJ. Secondary antibody deficiency. Expert Rev Clin Immunol. (2014) 10:583-91. doi: 10.1586/1744666X.2014.902314

169. Curry B, Palmer E, Mounce C, Smith G, Shah V. Assessing prescribing practices of clozapine before and after the implementation of an updated risk evaluation and mitigation strategy. Mental Health Clin. (2018) 8:63-7. doi: $10.9740 / \mathrm{mhc} .2018 .03 .063$

170. Kotton CN, Kumar D, Caliendo AM, Huprikar S, Chou S, Danziger-Isakov $\mathrm{L}$, et al. The Third International Consensus Guidelines on the Management of Cytomegalovirus in Solid-organ Transplantation. Transplantation (2018) 102:900-31. doi: 10.1097/TP.0000000000002191

171. Asgari E, Zhou W, Sacks S. Complement in organ transplantation. Curr Opin Organ Transplant. (2010) 15:486-91. doi: 10.1097/MOT.0b013e32833 b9cb7

172. Fernandez-Ruiz M, Kumar D, Humar A. Clinical immune-monitoring strategies for predicting infection risk in solid organ transplantation. Clin Transl Immunol. (2014) 3:e12. doi: 10.1038/cti.2014.3

173. Fernandez-Ruiz M, Lopez-Medrano F, Varela-Pena P, Morales JM, GarciaReyne A, San Juan R, et al. Hypocomplementemia in kidney transplant recipients: impact on the risk of infectious complications. Am J Transplant. (2013) 13:685-94. doi: 10.1111/ajt.12055

174. Carbone J, Micheloud D, Salcedo M, Rincon D, Banares R, Clemente G, et al. Humoral and cellular immune monitoring might be useful to identify liver transplant recipients at risk for development of infection. Transpl Infect Dis. (2008) 10:396-402. doi: 10.1111/j.1399-3062.2008.00329.x

175. Sarmiento E, del Pozo N, Gallego A, Fernandez-Yanez J, Palomo J, Villa A, et al. Decreased levels of serum complement C3 and natural killer cells add to the predictive value of total immunoglobulin $G$ for severe infection in heart transplant recipients. Transpl Infect Dis. (2012) 14:526-39. doi: 10.1111/j.1399-3062.2012.00757.x

176. Corales R, Chua J, Mawhorter S, Young JB, Starling R, Tomford JW, et al. Significant post-transplant hypogammaglobulinemia in six heart transplant recipients: an emerging clinical phenomenon? Transpl Infect Dis. (2000) 2:133-9. doi: 10.1034/j.1399-3062.2000.020306.x

177. Munoz P, Giannella M, Alcala L, Sarmiento E, Fernandez Yanez J, Palomo J, et al. Clostridium difficile-associated diarrhea in heart transplant recipients: is hypogammaglobulinemia the answer? J Heart Lung Transplant. (2007) 26:907-14. doi: 10.1016/j.healun.2007.07.010

178. Sarmiento E, Lanio N, Gallego A, Rodriguez-Molina J, Navarro J, Fernandez-Yanez J, et al. Immune monitoring of anti cytomegalovirus antibodies and risk of cytomegalovirus disease in heart transplantation. Int Immunopharmacol. (2009) 9:649-52. doi: 10.1016/j.intimp.2008. 09.013
179. Gennery AR, Cant AJ, Spickett GP, Walshaw D, Hunter S, Hasan A, et al. Effect of immunosuppression after cardiac transplantation in early childhood on antibody response to polysaccharide antigen. Lancet (1998) 351:1778-81. doi: 10.1016/S0140-6736(97)08486-9

180. Gennery AR, Barge D, Spickett GP, Cant AJ. Lymphocyte subset populations in children with polysaccharide antibody deficiency following cardiac transplantation. J Clin Immunol. (2001) 21:37-42. doi: 10.1023/A:1006741015452

181. Lazzarotto T, Varani S, Spezzacatena P, Pradelli P, Potena L, Lombardi A, et al. Delayed acquisition of high-avidity anti-cytomegalovirus antibody is correlated with prolonged antigenemia in solid organ transplant recipients. $J$ Infect Dis. (1998) 178:1145-9. doi: 10.1086/515671

182. Iberer F, Halwachs-Baumann G, Rodl S, Pleisnitzer A, Wasler A, Auer $\mathrm{T}$, et al. Monitoring of cytomegalovirus disease after heart transplantation: persistence of anti-cytomegalovirus IgM antibodies. J Heart Lung Transplant. (1994) 13:405-11.

183. Carbone J, Sarmiento E, Del Pozo N, Rodriguez-Molina JJ, Navarro J, Fernandez-Yanez J, et al. Restoration of humoral immunity after intravenous immunoglobulin replacement therapy in heart recipients with post-transplant antibody deficiency and severe infections. Clin Transplant. (2012) 26:E277-83. doi: 10.1111/j.1399-0012.2012.01653.x

184. Bunde T, Kirchner A, Hoffmeister B, Habedank D, Hetzer R, Cherepnev $\mathrm{G}$, et al. Protection from cytomegalovirus after transplantation is correlated with immediate early 1-specific CD8 T cells. J Exp Med. (2005) 201:1031-6. doi: $10.1084 /$ jem. 20042384

185. Tu W, Potena L, Stepick-Biek P, Liu L, Dionis KY, Luikart H, et al. T-cell immunity to subclinical cytomegalovirus infection reduces cardiac allograft disease. Circulation (2006) 114:1608-15. doi: 10.1161/CIRCULATIONAHA.105.607549

186. Sarmiento E, Navarro J, Fernandez-Yanez J, Palomo J, Munoz P, Carbone J. Evaluation of an immunological score to assess the risk of severe infection in heart recipients. Transpl Infect Dis. (2014) 16:802-12. doi: 10.1111/tid. 12284

187. Chong PP, Avery RK. A comprehensive review of immunization practices in solid organ transplant and hematopoietic stem cell transplant recipients. Clin Ther. (2017) 39:1581-98. doi: 10.1016/j.clinthera.2017.07.005

188. Broeders EN, Wissing KM, Ghisdal L, Lemy A, Hoang AD, Vereerstraeten $\mathrm{P}$, et al. Large decrease of anti-tetanus anatoxin and anti-pneumococcal antibodies at one year after renal transplantation. Clin Nephrol. (2013) 79:313-7. doi: $10.5414 / \mathrm{CN} 107779$

189. Frangoul H, Min E, Wang W, Chandrasekhar R, Calder C, Evans M, et al. Incidence and risk factors for hypogammaglobulinemia in pediatric patients following allo-SCT. Bone Marrow Transplant. (2013) 48:1456-9. doi: 10.1038/bmt.2013.76

190. Witherspoon RP, Storb R, Ochs HD, Fluornoy N, Kopecky KJ, Sullivan KM, et al. Recovery of antibody production in human allogeneic marrow graft recipients: influence of time posttransplantation, the presence or absence of chronic graft-versus-host disease, and antithymocyte globulin treatment. Blood (1981) 58:360-8.

191. Kuzmina Z, Greinix HT, Weigl R, Kormoczi U, Rottal A, Frantal S, et al. Significant differences in B-cell subpopulations characterize patients with chronic graft-versus-host disease-associated dysgammaglobulinemia. Blood (2011) 117:2265-74. doi: 10.1182/blood-2010-07-295766

192. Podgorny PJ, Liu Y, Dharmani-Khan P, Pratt LM, Jamani K, Luider $\mathrm{J}$, et al. Immune cell subset counts associated with graft-versushost disease. Biol Blood Marrow Transplant. (2014) 20:450-62. doi: 10.1016/j.bbmt.2014.01.002

193. Terpos E, Kleber M, Engelhardt M, Zweegman S, Gay F, Kastritis E, et al. European Myeloma Network guidelines for the management of multiple myeloma-related complications. Haematologica (2015) 100:125466. doi: 10.3324 /haematol.2014.117176

194. Rubin LG, Levin MJ, Ljungman P, Davies EG, Avery R, Tomblyn $\mathrm{M}$, et al. 2013 IDSA clinical practice guideline for vaccination of the immunocompromised host. Clin Infect Dis. (2014) 58:e44-100. doi: 10.1093/cid/cit684

195. Bonten MJ, Huijts SM, Bolkenbaas M, Webber C, Patterson S, Gault S, et al. Polysaccharide conjugate vaccine against pneumococcal pneumonia in adults. N Engl J Med. (2015) 372:1114-25. doi: 10.1056/NEJMoa1408544 
196. Anderson KC, Alsina M, Atanackovic D, Biermann JS, Chandler JC, Costello C, et al. Multiple myeloma, version 2.2016: clinical practice guidelines in oncology. J Natl Compr Canc Netw. (2015) 13:1398-435. doi: $10.6004 /$ jnccn. 2015.0167

197. Duchini A, Goss JA, Karpen S, Pockros PJ. Vaccinations for adult solidorgan transplant recipients: current recommendations and protocols. Clin Microbiol Rev. (2003) 16:357-64. doi: 10.1128/CMR.16.3.357-364.2003

198. Broyer M, Tete MJ, Guest G, Gagnadoux MF, Rouzioux C. Varicella and zoster in children after kidney transplantation: long-term results of vaccination. Pediatrics (1997) 99:35-9. doi: 10.1542/peds.99.1.35

199. Danzinger-Isakov L, Kumar D, Practice ASTIDCo. Guidelines for vaccination of solid organ transplant candidates and recipients. Am J Transplant. (2009) 9(Suppl. 4):S258-62. doi: 10.1111/j.1600-6143.2009.02917.x

200. van Kessel DA, Hoffman TW, Kwakkel-van Erp JM, Oudijk ED, Zanen P, Rijkers GT, et al. Long-term follow-up of humoral immune status in adult lung transplant recipients. Transplantation (2017) 101:2477-83. doi: 10.1097/TP.0000000000001685

201. Lee S, Kim HW, Kim K-H. Antibodies against Hepatitis A and Hepatitis B virus in intravenous immunoglobulin products. J Korean Med Sci. (2016) 31:1937-42. doi: 10.3346/jkms.2016.31.12.1937

202. Nobre FA, Gonzalez IGdS, Simão RM, de Moraes Pinto MI, CostaCarvalho BT. Antibody levels to tetanus, diphtheria, measles and varicella in patients with primary immunodeficiency undergoing intravenous immunoglobulin therapy: a prospective study. BMC Immunol. (2014) 15:26. doi: 10.1186/1471-2172-15-26

203. Gilbert SC. T-cell-inducing vaccines - what's the future. Immunology (2012) 135:19-26. doi: 10.1111/j.1365-2567.2011.03517.x

204. National Center for Immunization and Respiratory Diseases. General recommendations on immunization - recommendations of the Advisory Committee on Immunization Practices (ACIP). MMWR Recomm Rep. (2011) 60:1-64. Available online at: https://www.cdc.gov/mmwr/preview/ mmwrhtml/rr6002a1.htm

205. Oscier D, Dearden C, Eren E, Fegan C, Follows G, Hillmen P, et al. Guidelines on the diagnosis, investigation and management of chronic lymphocytic leukaemia. Br J Haematol. (2012) 159:541-64. doi: 10.1111/bjh. 12067

206. Cooperative Group for the Study of Immunoglobulin in Chronic Lymphocytic Leukemia, Gale RP, Chapel HM, Bunch C, Rai KR, Foon K, et al. Intravenous immunoglobulin for the prevention of infection in chronic lymphocytic leukemia. A randomized, controlled clinical trial. N Engl J Med. (1988) 319:902-7. doi: 10.1056/NEJM198810063191403

207. Jurlander J, Geisler $\mathrm{CH}$, Hansen MM. Treatment of hypogammaglobulinaemia in chronic lymphocytic leukaemia by lowdose intravenous gammaglobulin. Eur J Haematol. (1994) 53:114-8. doi: 10.1111/j.1600-0609.1994.tb01874.x

208. Chapel H, Dicato M, Gamm H, Brennan V, Ries F, Bunch C, et al. Immunoglobulin replacement in patients with chronic lymphocytic leukaemia: a comparison of two dose regimes. Br J Haematol. (1994) 88:20912. doi: 10.1111/j.1365-2141.1994.tb05002.x

209. Sklenar I, Schiffman G, Jonsson V, Verhoef G, Birgens H, Boogaerts M, et al. Effect of various doses of intravenous polyclonal IgG on in vivo levels of 12 pneumococcal antibodies in patients with chronic lymphocytic leukaemia and multiple myeloma. Oncology (1993) 50:466-77. doi: 10.1159/0002 27231

210. Griffiths H, Brennan V, Lea J, Bunch C, Lee M, Chapel H. Crossover study of immunoglobulin replacement therapy in patients with low-grade B-cell tumors. Blood (1989) 73:366-8.

211. Boughton BJ, Jackson N, Lim S, Smith N. Randomized trial of intravenous immunoglobulin prophylaxis for patients with chronic lymphocytic leukaemia and secondary hypogammaglobulinaemia. Clin Lab Haematol. (1995) 17:75-80. doi: 10.1111/j.1365-2257.1995.tb00322.x

212. Molica S, Musto P, Chiurazzi F, Specchia G, Brugiatelli M, Cicoira L, et al. Prophylaxis against infections with low-dose intravenous immunoglobulins (IVIG) in chronic lymphocytic leukemia. Results of a crossover study. Haematologica (1996) 81:121-6.

213. National Institutes on Health. Consensus on IVIG. Lancet (1990) 336:470-2. doi: 10.1016/0140-6736(90)92016-B
214. European Medicines Agency. Guideline on Core SmPC for Human Normal Immunoglobulin for Intravenous Administration (IVIg): EMA (2018). Available online at: https://www.ema.europa.eu/documents/scientificguideline/guideline-core-smpc-human-normal-immunoglobulinintravenous-administration-ivig-rev-5_en.pdf (October 2018).

215. Besa EC, Klumpe D. Prophylactic immune globulin in chronic lymphocytic leukemia. N Engl J Med. (1992) 326:139. doi: 10.1056/NEJM199201093260216

216. Ammann EM, Jones MP, Link BK, Carnahan RM, Winiecki SK, Torner JC, et al. Intravenous immune globulin and thromboembolic adverse events in patients with hematologic malignancy. Blood (2016) 127:200-7. doi: 10.1182/blood-2015-05-647552

217. Stiehm ER. Adverse effects of human immunoglobulin therapy. Transfus Med Rev. (2013) 27:171-8. doi: 10.1016/j.tmrv.2013. 05.004

218. Ochs HD, Gupta S, Kiessling P, Nicolay U, Berger M, Subcutaneous Ig GSG. Safety and efficacy of self-administered subcutaneous immunoglobulin in patients with primary immunodeficiency diseases. J Clin Immunol. (2006) 26:265-73. doi: 10.1007/s10875-0069021-7

219. Wasserman RL, Melamed I, Nelson RP Jr, Knutsen AP, Fasano MB, Stein MR, et al. Pharmacokinetics of subcutaneous IgPro20 in patients with primary immunodeficiency. Clin Pharmacokinet. (2011) 50:405-14. doi: 10.2165/11587030-00000000000000

220. Jolles S. Subcutaneous and Intramuscular Immune Globulin Therapy (2018). Available online at: https://www.uptodate.com/contents/subcutaneous-andintramuscular-immune-globulin-therapy (Accessed January 15, 2019).

221. Gardulf A, Nicolay U, Math D, Asensio O, Bernatowska E, Bock $A$, et al. Children and adults with primary antibody deficiencies gain quality of life by subcutaneous IgG self-infusions at home. J Allergy Clin Immunol. (2004) 114:936-42. doi: 10.1016/j.jaci.2004. 06.053

222. Chapel H, Brennan V, Delson E. Immunoglobulin replacement therapy by self-infusion at home. Clin Exp Immunol. (1988) 73:160-2.

223. Sarmiento E, Diez P, Arraya M, Jaramillo M, Calahorra L, FernandezYanez J, et al. Early intravenous immunoglobulin replacement in hypogammaglobulinemic heart transplant recipients: results of a clinical trial. Transpl Infect Dis. (2016) 18:832-43. doi: 10.1111/tid. 12610

224. Yamani MH, Avery R, Mawhorter SD, McNeill A, Cook D, Ratliff NB, et al. The impact of CytoGam on cardiac transplant recipients with moderate hypogammaglobulinemia: a randomized single-center study. J Heart Lung Transplant. (2005) 24:1766-9. doi: 10.1016/j.healun.2004. 11.016

225. Carbone J, Sarmiento E, Palomo J, Fernandez-Yanez J, Munoz P, Bouza E, et al. The potential impact of substitutive therapy with intravenous immunoglobulin on the outcome of heart transplant recipients with infections. Transplant Proc. (2007) 39:2385-8. doi: $10.1016 /$ j.transproceed.2007.06.050

226. Sarmiento E, Fernandez-Yanez J, Munoz P, Palomo J, RodriguezMolina JJ, Bermejo J, et al. Hypogammaglobulinemia after heart transplantation: use of intravenous immunoglobulin replacement therapy in relapsing CMV disease. Int Immunopharmacol. (2005) 5:97-101. doi: $10.1016 /$ j.intimp.2004.09.006

227. European Medicines Agency. Guideline on the Clinical Investigation of Human Normal Immunoglobulin for Subcutaneous and/or Intramuscular Administration (SCIg/IMIg): EMA (2015). Available online at: http://www. ema.europa.eu/docs/en_GB/document_library/Scientific_guideline/2015/ 07/WC500190211.pdf (Accessed January 15, 2019).

228. Eichhorst B, Robak T, Montserrat E, Ghia P, Hillmen P, Hallek M, et al. Chronic lymphocytic leukaemia: ESMO Clinical Practice Guidelines for diagnosis, treatment and follow-up. Ann Oncol. (2015) 26(Suppl. 5):v78-84. doi: 10.1093/annonc/mdv303

229. Department of Health. Clinical Guidelines for Immunoglobulin Use (2011). Available online at: https://www.gov.uk/government/ uploads/system/uploads/attachment_data/file/216671/dh_131107.pdf (Accessed January 15, 2019). 
230. Australian National Blood Authority. Acquired Hypogammaglobulinaemia Secondary to Haematological Malignancies, or Post-Haemopoietic Stem Cell Transplantation (HSCT): BloodStar (2018). Available online at: https:// www.criteria.blood.gov.au/MedicalCondition/View/2570 (Accessed January $15,2019)$.

231. Australian National Blood Authority. Secondary Hypogammaglobulinaemia Unrelated to Haematological Malignancy or Haemopoeitic Stem Cell Transplant (HSCT): BloodStar (2018). Available online at: https://www. criteria.blood.gov.au/MedicalCondition/View/2577 (Accessed January 15, 2019).

232. Alberta Ministry of Health, Shared Health Manitoba, Saskatchewan Ministry of Health. Criteria for the Clinical Use of Immune Globulin (2018). Available online at: https://www.ihe.ca/download/criteria for_the_clinical_use_of_immune_globulin_first_edition.pdf (Accessed January 15, 2019).

233. Lumbreras C, Manuel O, Len O, ten Berge IJ, Sgarabotto D, Hirsch HH. Cytomegalovirus infection in solid organ transplant recipients. Clin Microbiol Infect. (2014) 20(Suppl. 7):19-26. doi: 10.1111/1469-0691.12594

234. Jolles S, Orange JS, Gardulf A, Stein MR, Shapiro R, Borte M, et al. Current treatment options with immunoglobulin $\mathrm{G}$ for the individualization of care in patients with primary immunodeficiency disease. Clin Exp Immunol. (2015) 179:146-60. doi: 10.1111/cei.12485

235. European Medicines Agency. Guideline on the Clinical Investigation of Human Normal Immunoglobulin for Intravenous Administration (IVIg): EMA (2018). Available online at: https://www.ema.europa.eu/documents/ scientific-guideline/guideline-clinical-investigation-human-normalimmunoglobulin-intravenous-administration-ivig-rev-3_en.pdf (Accessed January 15, 2019).

236. Streu E, Banerji V, Dhaliwal DHS. The efficacy and cost effectiveness of Subcutaneous Immunoglobulin (SCIG) replacement in patients with immune deficiency secondary to chronic lymphocytic leukemia. Blood (2016) 128:4778. Available online at: http://www.bloodjournal.org/content/ $128 / 22 / 4778$ ?sso- checked=true

237. Abolhassani H, Sagvand BT, Shokuhfar T, Mirminachi B, Rezaei N, Aghamohammadi A. A review on guidelines for management and treatment of common variable immunodeficiency. Expert Rev Clin Immunol. (2013) 9:561-75. doi: 10.1586/eci.13.30

238. Bonilla FA, Khan DA, Ballas ZK, Chinen J, Frank MM, Hsu JT, et al. Practice parameter for the diagnosis and management of primary immunodeficiency. J Allergy Clin Immunol. (2015) 136:1186-205.e78. doi: 10.1016/j.jaci.2015.04.049

239. Immune Deficiency Foundation. Diagnostic \& Clinical Care Guidelines for Primary Immunodeficiency Diseases (2009). Available online at: https://primaryimmune.org/wp-content/uploads/2011/04/IDF-DiagnosticClinical-Care-Guidelines-for-Primary-Immunodeficiency-Diseases-2ndEdition.pdf (Accessed January 15, 2019).

240. Evans C, Bateman E, Steven R, Ponsford M, Cullinane A, Shenton C, et al. Measurement of Typhim Vi antibodies can be used to assess adaptive immunity in patients with immunodeficiency. Clin Exp Immunol. (2018) 192:292-301. doi: 10.1111/cei.13105

241. Parker AR, Bradley C, Harding S, Sánchez-Ramón S, Jolles S, Kiani-Alikhan S. Measurement and interpretation of Salmonella typhi Vi IgG antibodies for the assessment of adaptive immunity. J Immunol Methods (2018) 459:1-10. doi: 10.1016/j.jim.2018.05.013

242. Jolles S, Borrell R, Zouwail S, Heaps A, Sharp H, Moody M, et al. Calculated globulin (CG) as a screening test for antibody deficiency. Clin Exp Immunol. (2014) 177:671-8. doi: 10.1111/cei.12369

243. Holding S, Jolles S. Current screening approaches for antibody deficiency. Curr Opin Allergy Clin Immunol. (2015) 15:547-55. doi: 10.1097/ACI.0000000000000222

244. Smith J, Fernando T, McGrath N, Ameratunga R. Lamotrigine-induced common variable immune deficiency. Neurology (2004) 62:833-4. doi: 10.1212/01.WNL.0000113754.29225.5D

245. Yu KK, Dasanu CA. Rapidly fatal dissemination of merkel cell carcinoma in a patient treated with alemtuzumab for chronic lymphocytic leukemia. Conn Med. (2016) 80:353-8.
246. Uhm J, Hamad N, Gupta V, Kuruvilla J, Messner HA, Seftel M, et al. The risk factors for IgG hypogammaglobulinemia after allogeneic hematopoietic stem cell transplantation and its impact on transplant outcomes. Blood (2014) 124:3928. Available online at: http://www.bloodjournal.org/content/124/21/ 3928? sso- checked=true

247. Hlavackova E, Liska M, Jicinska H, Navratil J, Litzman J. Secondary combined immunodeficiency in pediatric patients after the fontan operation: three case reports Int Arch Allergy Immunol. 2016; 170: 251-6 doi: $10.1159 / 000449163$

248. Norlin AC, Sairafi D, Mattsson J, Ljungman P, Ringdén O, Remberger M. Allogeneic stem cell transplantation: low immunoglobulin levels associated with decreased survival. Bone Marrow Transplant. (2008) 41:267-73. doi: 10.1038/sj.bmt.1705892

249. Stiehm ER. Use of immunoglobulin therapy in secondary antibody deficiencies. In: Imbach P, Nydegger UE, Morell A, et al., editors. Immunotherapy With Intravenous Immunoglobulins. London: Academic Press (1991). p. 115-26. doi: 10.1016/B978-0-12-370725-3. 50015-4

250. Hodge D, Misbah SA, Mueller RF, Glass EJ, Chetcuti PA. Proteus syndrome and immunodeficiency. Arch Dis Child. (2000) 82:234-5. doi: 10.1136/adc.82.3.234

251. Hargreaves RM, Lea JR, Griffiths H, Faux JA, Holt JM, Reid C, et al. Immunological factors and risk of infection in plateau phase myeloma. J Clin Pathol. (1995) 48:260-6. doi: 10.1136/jcp.48.3.260

252. Chakrabarti S, Keeton BR, Salmon AP, Vettukatti JJ. Acquired combined immunodeficiency associated with protein losing enteropathy complicating Fontan operation. Heart (2003) 89:1130-1. doi: 10.1136/heart.89.1 0.1130

253. Dominguez-Pinilla N, Benitez EM, Gonzalez-Tome MI, RuizContreras J, Gonzalez-Granado LI. Invasive pneumococcal infection secondary to hypogammaglobulinemia due to Menetrier disease. Pediatr Infect Dis J. (2013) 32:578. doi: 10.1097/INF.0b013e31828 15064

254. Kaminsky P, Lesesve JF, Jonveaux P, Pruna L. IgG deficiency and expansion of CTG repeats in myotonic dystrophy. Clin Neurol Neurosurg. (2011) 113:464-8. doi: 10.1016/j.clineuro.2011. 02.003

255. Santachiara R, Maffei R, Martinelli S, Arcari A, Piacentini F, Trabacchi E, et al. Development of hypogammaglobulinemia in patients treated with imatinib for chronic myeloid leukemia or gastrointestinal stromal tumor. Haematologica (2008) 93:1252-5. doi: 10.3324/haematol. 12642

256. Srivannaboon K, Conley ME, Coustan-Smith E, Wang WC. Hypogammaglobulinemia and reduced numbers of B-cells in children with myelodysplastic syndrome. J Pediatr Hematol Oncol. (2001) 23:122-5. doi: 10.1097/00043426-200102000-00011

257. Braamskamp MJAM, Dolman KM, Tabbers MM. Clinical practice: proteinlosing enteropathy in children. Eur J Pediatrics (2010) 169:1179-85. doi: 10.1007/s00431-010-1235-2

Conflict of Interest Statement: SJ has participated in advisory boards, trials, projects, and has been a speaker with Baxalta, CSL Behring, Shire, Thermofisher, Swedish Orphan Biovitrum, Biotest, Binding Site, Grifols, BPL, Octapharma, LFB, GSK, Weatherden, Zarodex, Sanofi, and UCB Pharma. SP has been a speaker for CSL and Biotest. JC has participated in advisory boards and projects, and has been a speaker for Grifols, Biotest, Shire, LFB, CSL Behring, Octapharma. He has a grant from the Instituto de Salud Carlos III FIS 1501472 with participation of FEDER funds, a way of making Europe.

Copyright (๑) 2019 Patel, Carbone and Jolles. This is an open-access article distributed under the terms of the Creative Commons Attribution License (CC BY). The use, distribution or reproduction in other forums is permitted, provided the original author(s) and the copyright owner(s) are credited and that the original publication in this journal is cited, in accordance with accepted academic practice. No use, distribution or reproduction is permitted which does not comply with these terms. 